\title{
Full-Process Radiosensitization Based on Nanoscale
}

\section{Metal-Organic Frameworks}

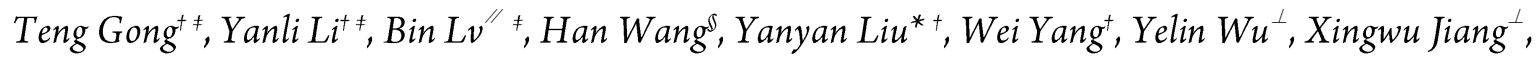
Hongbo Gao", Xiangpeng Zheng* " and Wenbo Bu $u^{*+s}$

$\uparrow$ Shanghai Key Laboratory of Green Chemistry and Chemical Processes, School of Chemistry and Molecular Engineering, East China Normal University, Shanghai 200062, China

"Department of Radiation Oncology, Shanghai Huadong Hospital, Fudan University, Shanghai 200040, China

§State Key Laboratory of High-Performance Ceramics and Superfine Microstructure, Shanghai Institute of Ceramics, Chinese Academy of Science, Shanghai, 200050, China

${ }^{\perp}$ Tongji University Cancer Center, Shanghai Tenth People’s Hospital, Tongji University School of Medicine, Shanghai 200072, China 


\section{Section 1: Methods}

UV-Vis spectroscopy. The spectra were determined using SHIMADZU UV-2700 spectrometer. Solid-state spectroscopy was conducted using a diffuse reflectance (DR) attachment including ISR-2600 integrating sphere, with $\mathrm{BaSO}_{4}$ as the reference (100\% reflectance). The sample powder was spread as a thin uniform layer on a layer of $\mathrm{BaSO}_{4}$ powder. The spectra were given in the form of effective absorbance. The energy gaps for CT transitions were estimated from the Tauc plots of $(F(\mathrm{R}) h v)^{1 / 2}$ against $h v$, where $F(\mathrm{R})$ is the Kubelka-Munk Function $[F(\mathrm{R})=(1$ $\mathrm{R})^{2} / 2 \mathrm{R}$ ] and $\mathrm{R}$ is the diffuse reflectance relative to $\mathrm{BaSO}_{4}$ (Figure $\left.\mathrm{S} 18 \mathrm{~b}\right){ }^{1,2}$

Electrochemical measurements. Cyclic voltammetry (CV) was conducted with CHI 604E workstation ( $\mathrm{CH}$ instruments, China) with a conventional three-electrode system, a MOFmodified glassy carbon electrode (GCE) as the working electrode, a platinum wire as the counter electrode, and an $\mathrm{Ag} / \mathrm{AgCl}$ electrode as the reference electrode. The supporting electrolyte was $0.1 \mathrm{M} \mathrm{KCl}$ aqueous solution, and the scan rate was set as $100 \mathrm{mV} \mathrm{s}^{-1}$. The modified GCE was fabricated as follows: $1 \mathrm{mg}$ of a ground nMOF sample was dispersed in $0.5 \mathrm{~mL}$ of ethanol and 40 $\mu \mathrm{L}$ of Nafion solution (5 wt. \% in lower aliphatic alcohols and water, contains $15-20 \%$ water) by sonication for 20 min. A pre-cleaned GCE was drop-cast with a $10 \mu \mathrm{L}$ portion of the dispersion and then dried in air. 


\section{Section 2: Biological characterization}

Cells and animals. HeLa, A549 and RM-1 cells were purchased from Shanghai Institute of cells, Chinese Academy of Sciences. Culture medium was composed of high-glucose Dulbecco's modified Eagle's medium (DMEM), 10\% fetal bovine serum (FBS), 1\% penicillin (100 U/mL), and streptomycin $(100 \mathrm{mg} / \mathrm{mL})$. Kunming mice and Balb/c nude mice were purchased from Shanghai SLAC Laboratory Animal Co. Ltd. These mice were raised in Laboratory Animal Center of East China Normal University (ECNU), for more than 8 weeks after birth. All the experiments conformed to animal ethics.

MTT assay. The Hela cells were seeded in 96-well plates and incubated with a series of concentrations of Hf-BPY or Hf-BPY-Fe for 24h. There were 6 wells in each group. 3-(4, 5dimethyl-2-thiazolyl)-2,5-diphenyl-2-H-tetrazolium bromide (MTT) cell survival assay was applied to measure the survival rate of cells in each group.

The cytotoxicity of $\mathrm{H}_{2} \mathrm{O}_{2}$ with nMOFs (5 ppm based $\mathrm{Hf}^{4+}$ ion) or without nMOFs to Hela cells in $24 \mathrm{~h}$ after incubation with the concentration of $0,12.5,25,50,100 \mu \mathrm{M}$ was measured by MTT assay. Based on this, the safe concentration of $\mathrm{H}_{2} \mathrm{O}_{2}$ used in subsequent cell experiments is 50 $\mu \mathrm{M}$.

Cytotoxicity of chemodynamic therapy (CDT) combined with RT was also based on MTT method. Briefly, Hela cells and $50 \mu \mathrm{M} \mathrm{H}_{2} \mathrm{O}_{2}$ were incubated with a series of concentrations of nMOFs $\left(0,5,20,40,80 \mathrm{ppm}\right.$ based $\mathrm{Hf}^{4+}$ ion $)$ for $24 \mathrm{~h}$. Then, the cells were irradiated with $0 \mathrm{~Gy}$ and $4 \mathrm{~Gy}$ of X-rays. After irradiation, cells continued to incubate for $24 \mathrm{~h}$ without changing culture medium. MTT cell survival assay was applied to measure the survival rate of cells in each group. 
Cellar uptake. FITC and nMOFs were mixed in ethanol and stirred for $6 \mathrm{~h}$ to get the FITC@ nMOFs. $1 \times 10^{4}$ Hela cells were seeded in $35 \mathrm{~mm}$ culture dishes and incubated with FITC@ nMOFs for $4 \mathrm{~h}$. After removing culture solution, the cells were washed for 3 times by phosphate buffer saline (PBS) was used to wash. The cells were fixed with $4 \%$ formaldehyde, labeled with DAPI, and then imaged by a confocal fluorescence microscope.

Cell cycle analysis. $1 \mathrm{ml}$ culture medium contained $1 \times 10^{5} \mathrm{HeLa}$ cells and $50 \mu \mathrm{M} \mathrm{H}_{2} \mathrm{O}_{2}$ with 5 ppm (based $\mathrm{Hf}^{4+}$ ion) Hf-BPY, 5 ppm (based $\mathrm{Hf}^{4+}$ ion) Hf-BPY-Fe or PBS were seeded in 6well plates and incubated for $24 \mathrm{~h}$. After incubation, those cells were collected by centrifugation (1000 rpm, $3 \mathrm{~min}$ ), washed twice with PBS, and then fixed with $70 \%$ precooled ethanol at $4{ }^{\circ} \mathrm{C}$ for $12 \mathrm{~h}$. Then the cells were incubated with RNase A (100 $\mu \mathrm{g} / \mathrm{mL})$ and propidium iodide (PI, $50 \mu \mathrm{g} / \mathrm{mL}$ ) for $30 \mathrm{~min}$ at $37{ }^{\circ} \mathrm{C}$ in the dark. The flow cytometry assay was employed for cell cycle analysis, and Modfit software was used for fitting analysis.

PCR Analysis. $5 \times 10^{4} \mathrm{HeLa}$ cells were seeded in several $35 \mathrm{~mm}$ culture dishes and incubated for $24 \mathrm{~h}$. These cells were irradiated with $6 \mathrm{~Gy}$ of X-rays. Then, the survival cells were replanted in new culture medium (containing $50 \mu \mathrm{M} \mathrm{H}_{2} \mathrm{O}_{2}$ ) and co-cultured with 5 ppm (based $\mathrm{Hf}^{4+}$ ion) Hf-BPY, Hf-BPY-Fe or PBS for different times (1 h, 6 h, 12 h and 24h), respectively. The ABI 7300 real-time PCR system was used for quantitative PCR measurement. The primer for the target genes were as follows:

\begin{tabular}{|l|l|}
\hline Gen & Primer sequences $\left(\mathbf{5}^{\prime}\right.$-3' ${ }^{\prime}$ ) \\
\hline H-GAPDH-S & GGAAGCTTGTCATCAATGGAAATC \\
\hline H-GAPDH-A & TGATGACCCTTTTGGCTCCC \\
\hline H-53BP1-S & ACGAGGAGACGGTAATAGTGGG \\
\hline H-53BP1-A & TGCTTGTCCTGTTTGGCTGA \\
\hline H-XRCC1-S & TGAACCAAGAAGAAAAGAAGACCC \\
\hline H-XRCC1-A & GGAAGCCACTCAGCACCACTA \\
\hline H-RAD51-S & ACCCATTTCACGGTTAGAGCA \\
\hline H-RAD51-A & CTTCTTTGGCGCATAGGCAAC \\
\hline
\end{tabular}


Colony formation assay. $2 \mathrm{ml}$ culture medium contained $50 \mu \mathrm{M} \mathrm{H}_{2} \mathrm{O}_{2}$ and 200 , 400, or 800 HeLa cells with 5 ppm (based $\mathrm{Hf}^{4+}$ ion) Hf-BPY, Hf-BPY-Fe, or PBS were seeded in 6-well plates. After incubation for 24 h, 200 cells wells were irradiated with 0 Gy or 2 Gy of X-rays, 400 cells were irradiated with 4 Gy of X-rays, and 800 cells were irradiated with 6 Gy of X-rays. Three parallel experiments were conducted in each group. After irradiation, all the plates were cultivated for 14 days. At last all cells were stained with giemsa stain. A cell colony should contain at least 50 cells. The sensitive enhancement ratio (SER) was evaluated by the multitarget and single-hit model, ${ }^{3}$

$$
y=1-\left(1-e^{-k x}\right)^{N}
$$

in which $x$ is the dosage of each group, and $y$ is colony formation rate. Then y value of the group treated with $4 \mathrm{~Gy}$ and saline was substituted into the equation for the other groups to calculate $x$. SER $=4$ Gy $/ x$ for each group. Clonogenic assays of A549 and RM-1 cells were performed using the same procedure.

Comet assay. $1 \mathrm{ml}$ culture medium contained $1 \times 10^{5} \mathrm{HeLa}$ cells and $50 \mu \mathrm{M} \mathrm{H}_{2} \mathrm{O}_{2}$ with $5 \mathrm{ppm}$ (based $\mathrm{Hf}^{4+}$ ion) Hf-BPY, Hf-BPY-Fe, or PBS were seeded in 6-well plates and incubated for 24 h. Then these cells were irradiated with $0 \mathrm{~Gy}$, or $4 \mathrm{~Gy}$ of X-rays. After incubation for $24 \mathrm{~h}$, the cells were centrifuged and washed twice with PBS. Finally, cells were digested and harvested, and the standard single cell gel electrophoresis procedure was employed to observe the DNA damage.

Apoptosis assay. $1 \mathrm{ml}$ culture medium contained $1 \times 10^{5} \mathrm{HeLa}$ cells and $50 \mu \mathrm{M} \mathrm{H}_{2} \mathrm{O}_{2}$ with 5 ppm (based $\mathrm{Hf}^{4+}$ ion) Hf-BPY, Hf-BPY-Fe, or PBS were seeded in 6-well plates and incubated for $24 \mathrm{~h}$. Then these cells were irradiated with $0 \mathrm{~Gy}$, or $4 \mathrm{~Gy}$ of X-rays. After incubation for $24 \mathrm{~h}$, the cells were centrifuged and washed twice with PBS. The suspended cells were added with 500 
$\mu \mathrm{L}$ binding buffer solution, and Annexin V-FITC was added for 15 min incubation in the dark. Before test, PI was added and incubated for 5 min. At last, the flow cytometry assay was employed, and Flowjo software was used for fitting analysis.

Western blotting for detection of protein expression. The cells were seeded and treated the same as cell apoptosis assay. After that, the cells were centrifuged and washed twice with PBS. Then the cells were lysed by pre-cooled RIPA buffer on ice. The protein samples were separated by SDS-PAGE (10\% gel) and transferred onto nitrocellulose membranes (PVDF). After blocking with $5 \%$ non-fat milk, the membranes were incubated with specific primary antibodies $(1: 1000)$ overnight at $4{ }^{\circ} \mathrm{C}$. After 3 times washing, incubations with secondary HRP-linked antibodies were performed at room temperature for $1 \mathrm{~h}$. Lastly, the membranes were detected using the electrochemiluminescence (ECL) reagent kit (Thermo Scientific, USA) according to manufacturer instruction.

In vivo toxicity assay. Kunming mice (7 weeks, female) were intravenous injected with HfBPY-Fe (Hf, $100 \mathrm{mg} / \mathrm{kg}$ ) suspended in normal saline and sacrificed at 3 or 30 days to collect blood for hematological assay and tissues (including heart, liver, spleen, lung, and kidney) for hematoxylin and eosin stain (H\&E stain). The control group received intravenous normal saline only and sacrificed at 3 or 30 days for the same assays.

In vivo radiation therapy. To establish the bilateral xenograft tumor model, $5 \times 10^{6}$ Hela cells were suspended in $100 \mu \mathrm{l}$ PBS and injected subcutaneously into the flanks of Balb/c nude mice (7 weeks, female). As the tumor size reached approximately $100 \mathrm{~mm}^{3}$, the mice were divided randomly into 4 groups (6 mice in each group). Three groups received intratumoral objection of PBS, Hf-BPY (Hf, $20 \mathrm{mg} / \mathrm{kg}$ ), and Hf-BPY-Fe (Hf, $20 \mathrm{mg} / \mathrm{kg}$ ), respectively. After $24 \mathrm{~h}$, tumors in the right flank were irradiated at a dose of $4 \mathrm{~Gy}$, and tumors in the left flank were shielded 
from irradiation as the control. The H\&E stain and TdT mediated dUTP nick end labeling (TUNEL) of tumor tissues using a commercially available kit were performed at $48 \mathrm{~h}$ after irradiation, respectively. Body weight of mice and tumor volume were recorded every 3 days, and the latter was calculated by the following equation: volume $=$ length $\times(\text { width })^{2} / 2$. The other three groups received intravenous administration of PBS, Hf-BPY-Fe (Hf, $20 \mathrm{mg} / \mathrm{kg}$ ), and PEGHf-BPY-Fe (Hf, $20 \mathrm{mg} / \mathrm{kg}$ ), respectively. The tumor volume were recorded every 3 days. 


\section{Section 3: Supplementary figures}

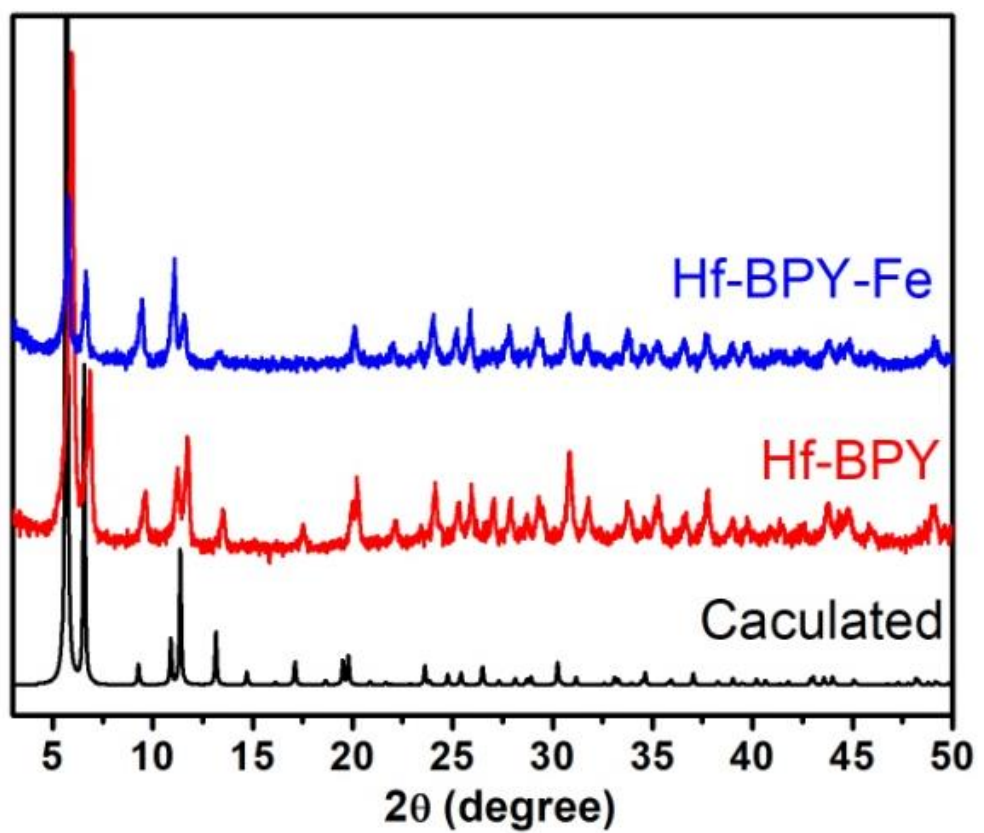

Figure S1. PXRD patterns of nMOFs.

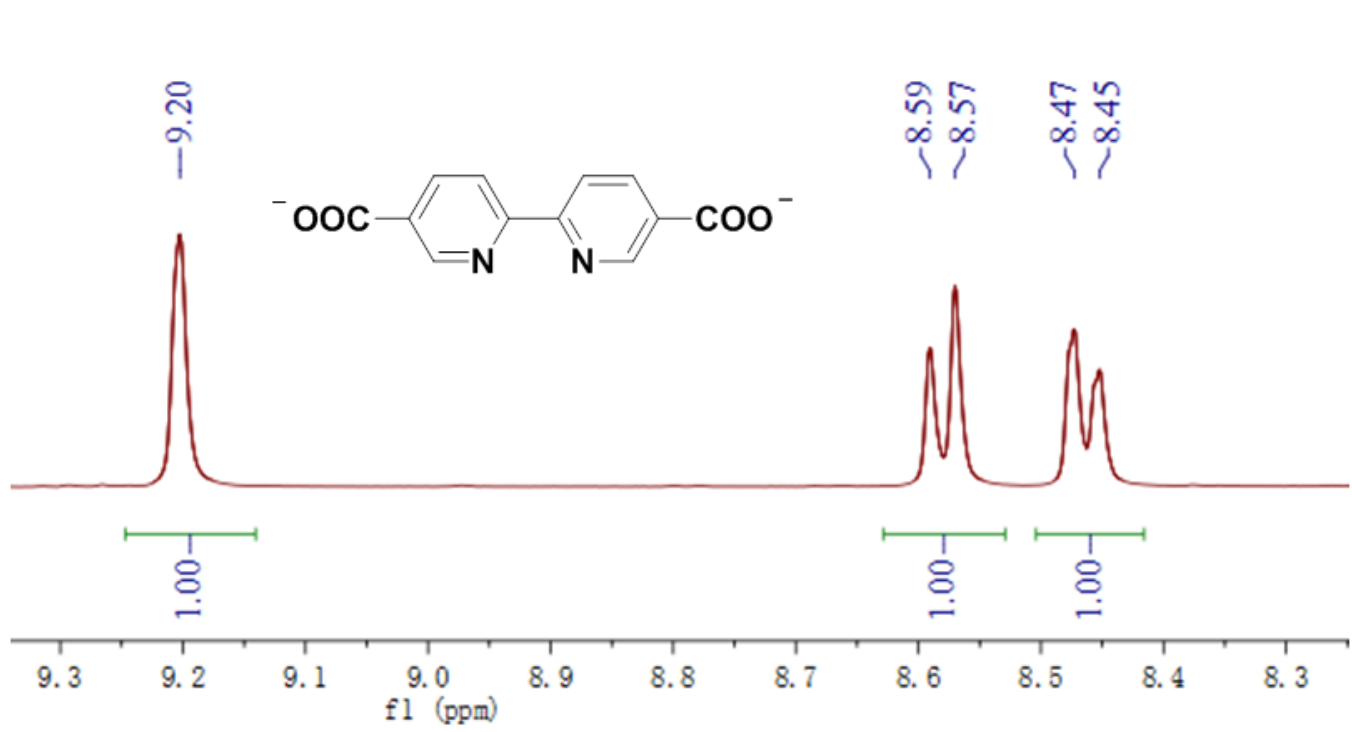

Figure S2. ${ }^{1} \mathrm{H}$ NMR spectrum of Hf-BPY. The spectrum was recorded with the solutions obtained by digesting the solids with HF (aq.)/d6-DMSO $\left(1 / 40\right.$, v/v). ${ }^{4}$ No other miscellaneous peaks were found, indicating the high purity of materials. 


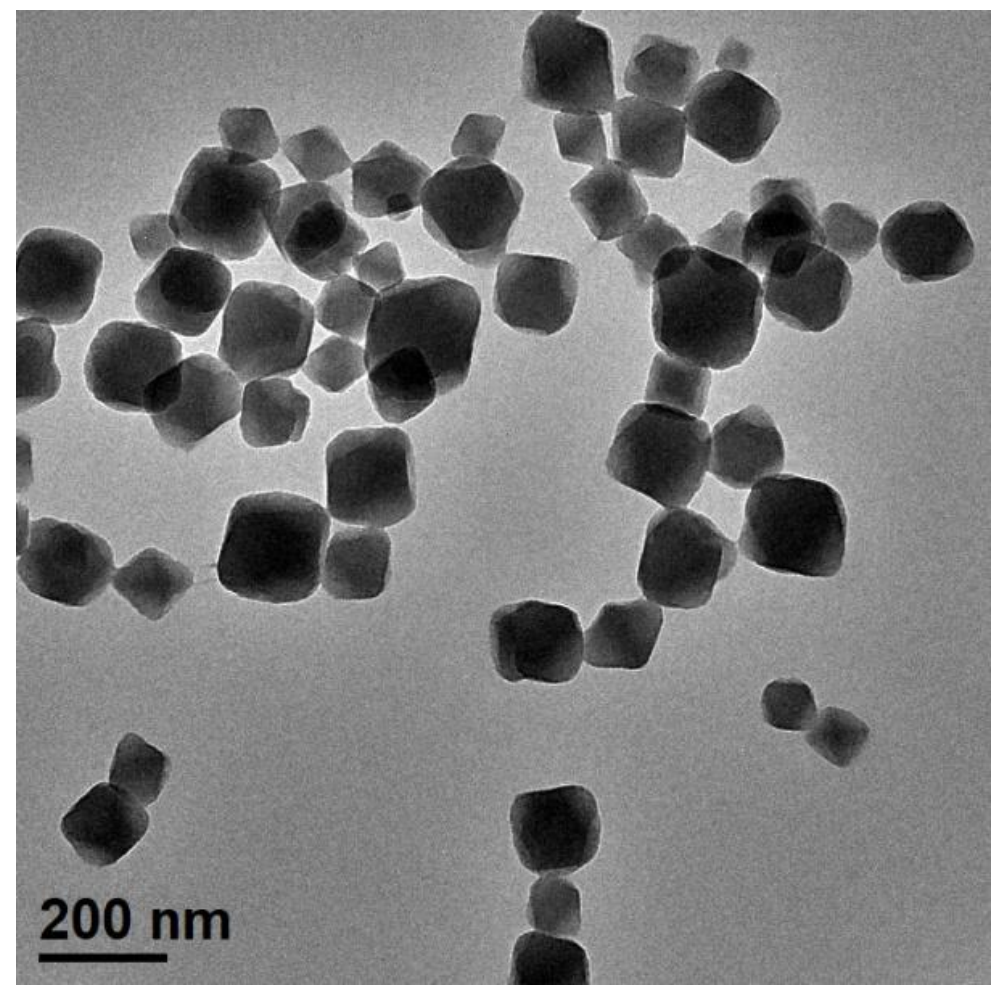

Figure S3. TEM image of Hf-BPY.

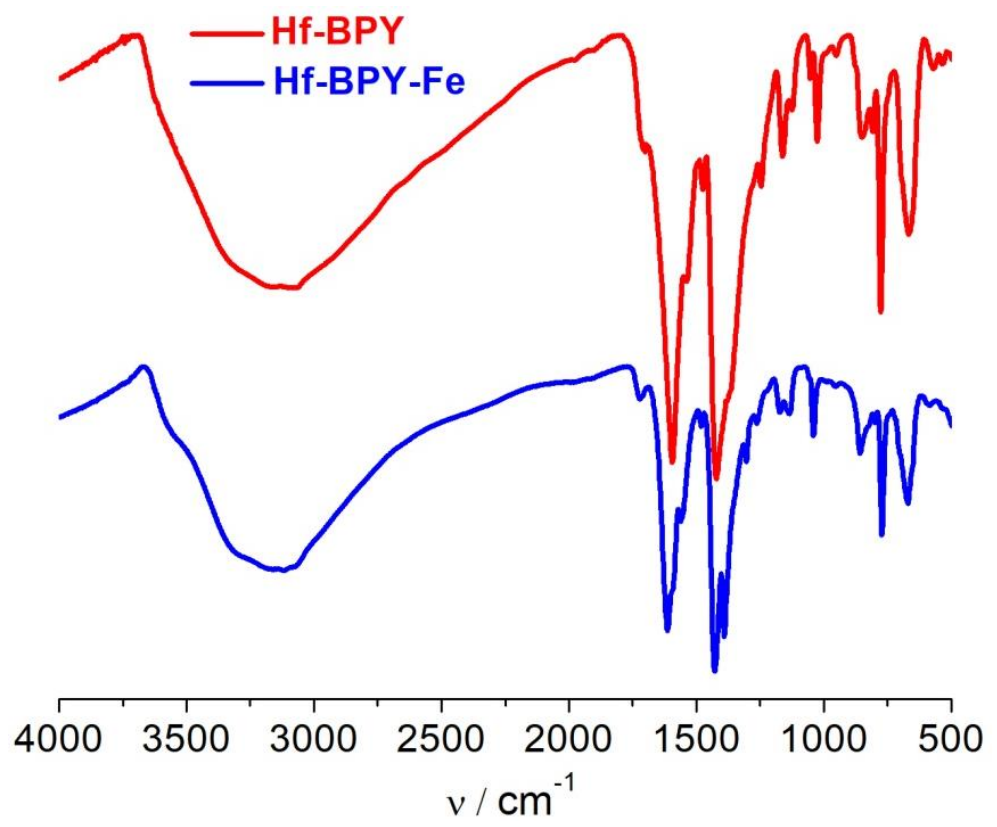

Figure S4. IR spectra of Hf-BPY and Hf-BPY-Fe. 


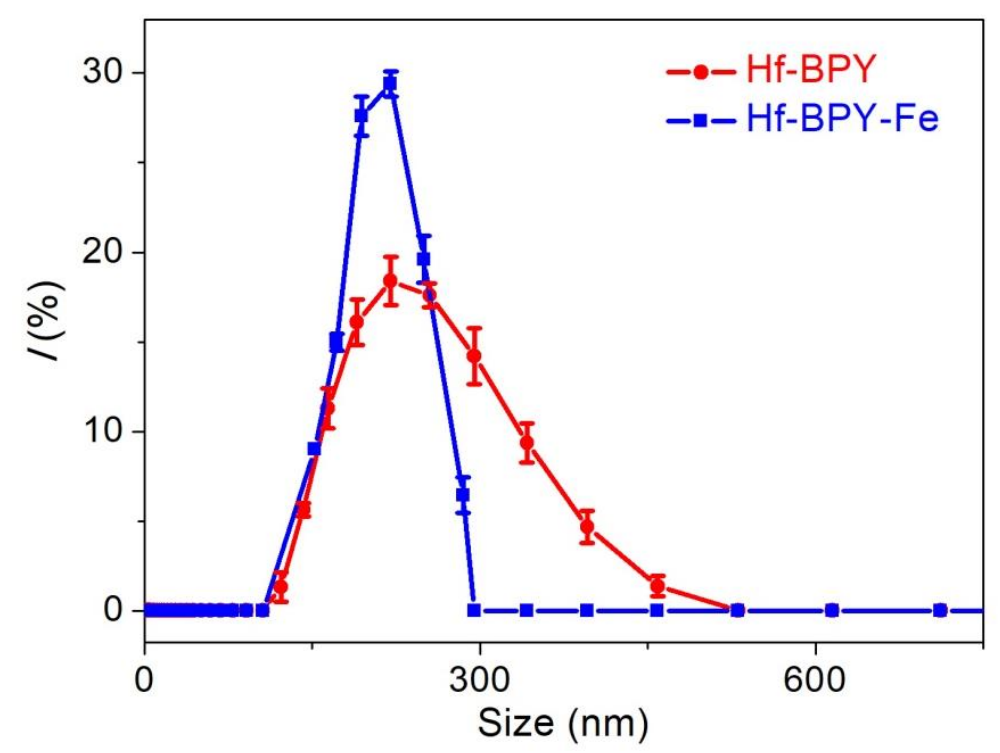

Figure S5. Particle size distributions of Hf-BPY and Hf-BPY-Fe.

(a)
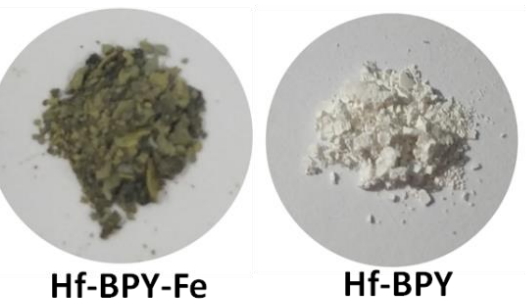

Hf-BPY-Fe

Hf-BPY

(b)

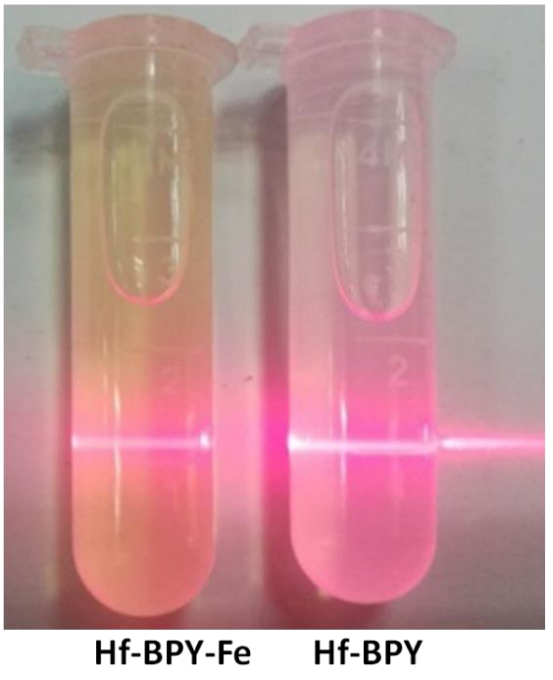

Figure S6. (a) Photographic images showing Hf-BPY and Hf-BPY-Fe polycrystalline samples.

(b) Photographs of saline dispersion for Hf-BPY and Hf-BPY-Fe. 


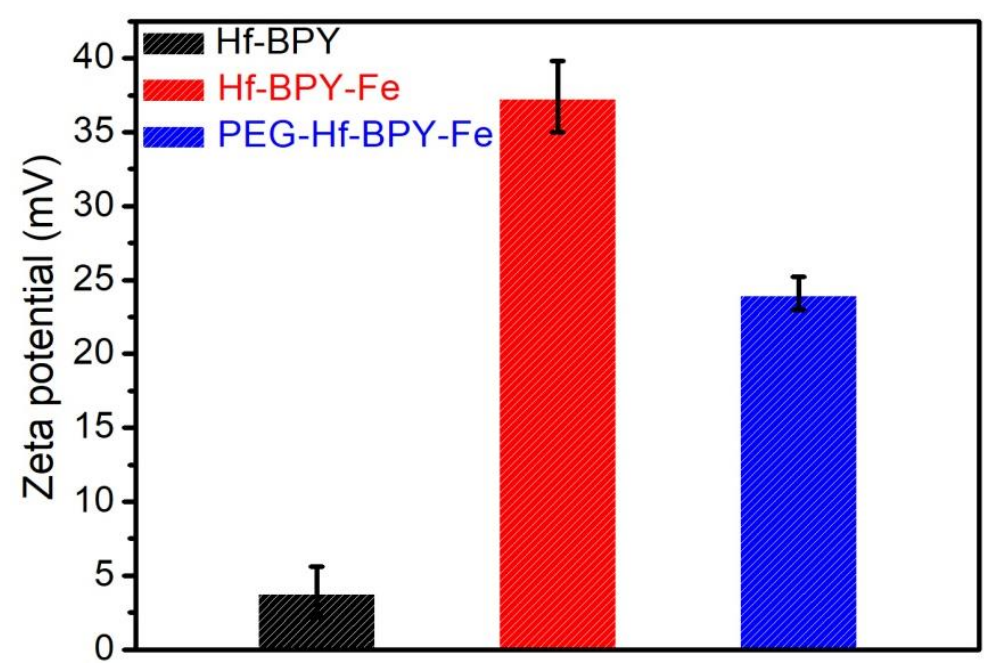

Figure S7. Zeta potentials of Hf-BPY, Hf-BPY-Fe and PEG-Hf-BPY-Fe.

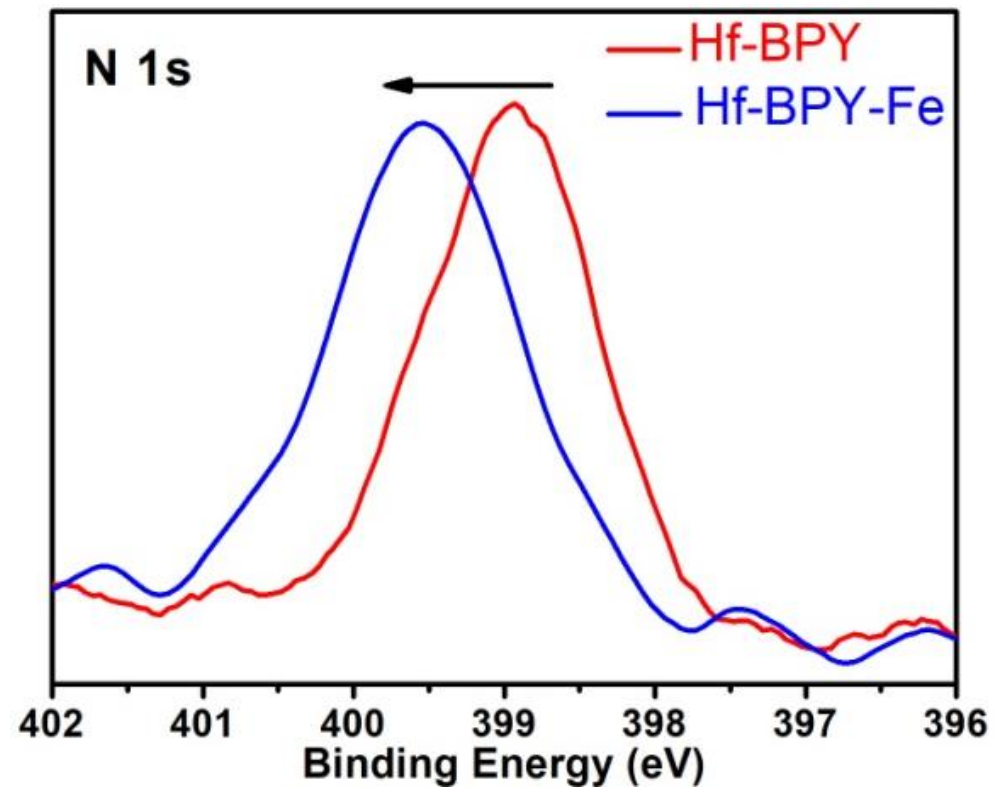

Figure S8. XPS spectra of Hf-BPY and Hf-BPY-Fe. 

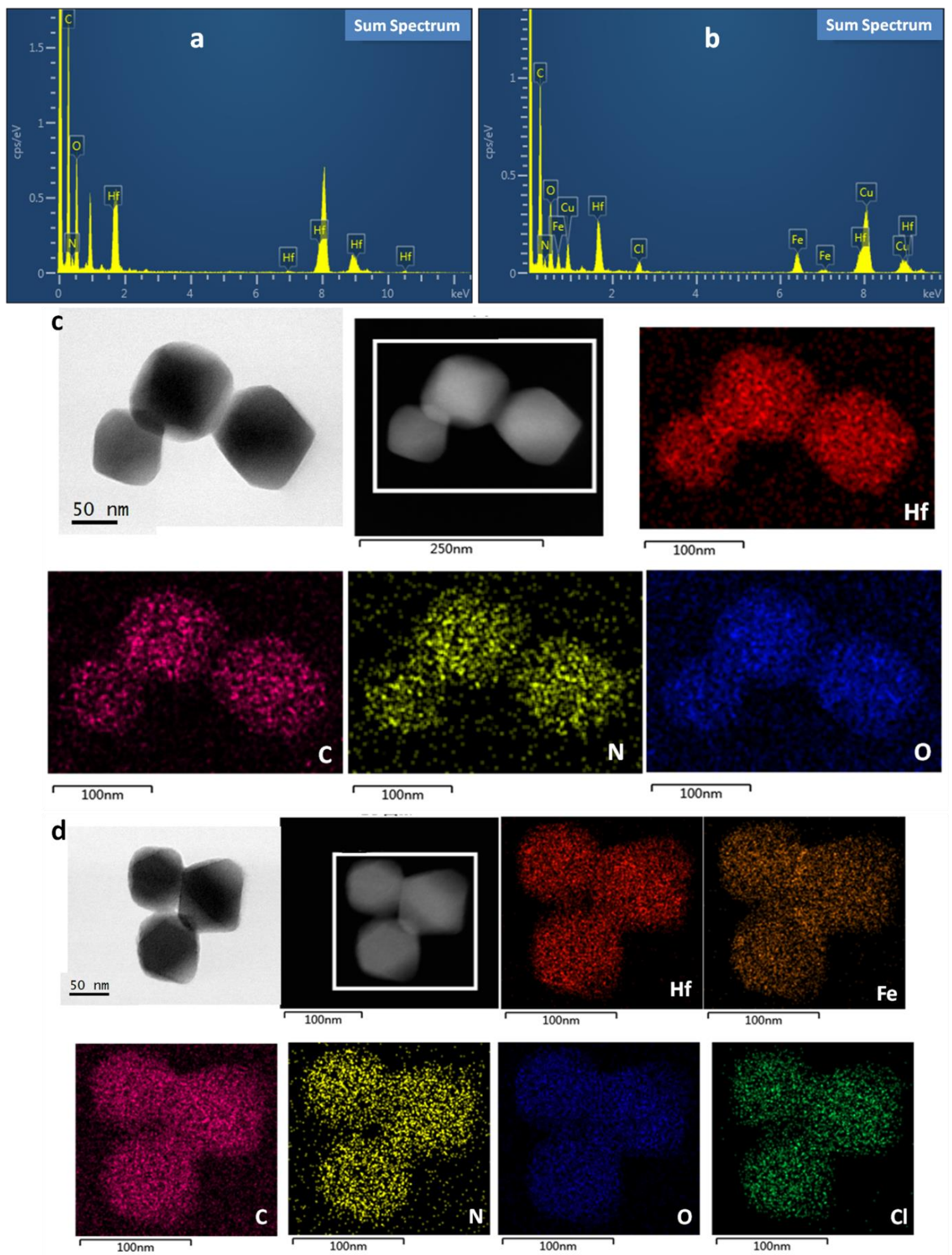

Figure S9. Elemental analysis and energy dispersive X-ray elemental mapping of Hf-BPY (a, c) and Hf-BPY-Fe (b, d). 


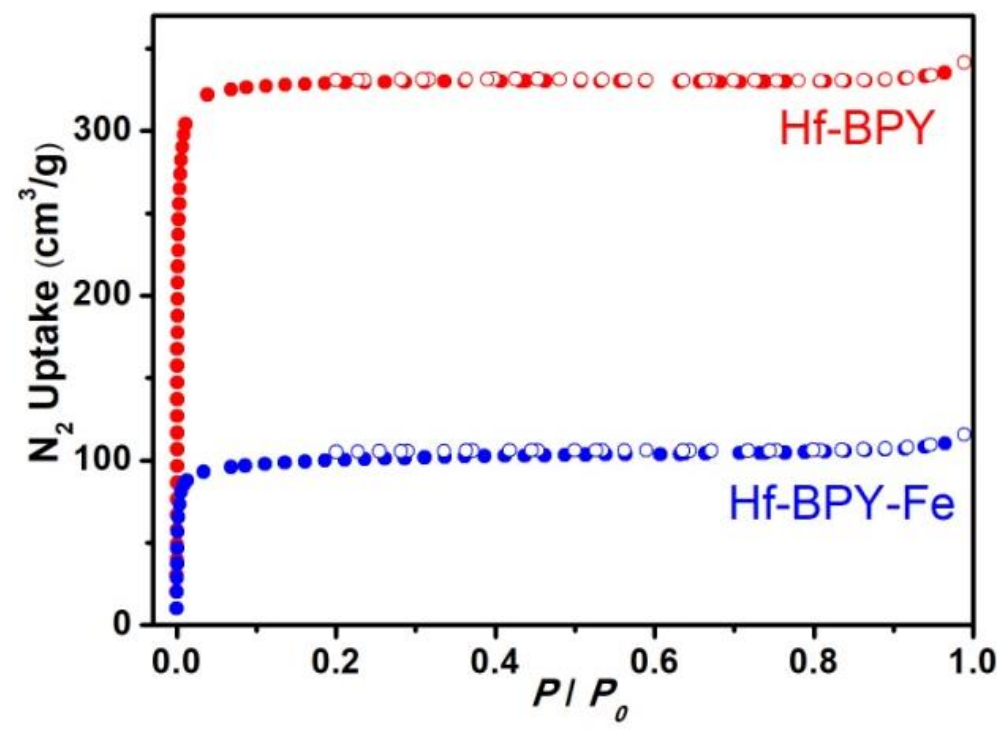

Figure S10. $\mathrm{N}_{2}$ adsorption/desorption isotherms of Hf-BPY and Hf-BPY-Fe.
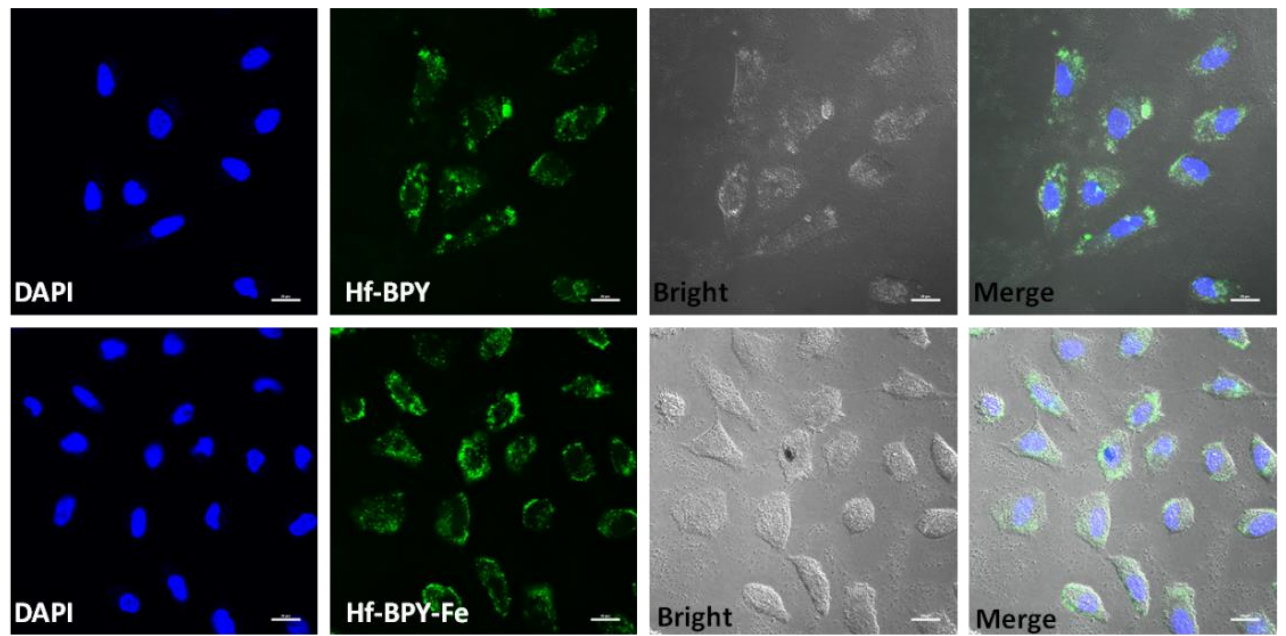

Figure S11. Assessment of cellular uptake of Hf-BPY and Hf-BPY-Fe (Scale bar $=20 \mu \mathrm{m}$ ). HeLa cells treated with FITC-labeled Hf-BPY and Hf-BPY-Fe showed remarkable intracellular green fluorescence spots. Nuclei were stained with DAPI (blue fluorescence). 

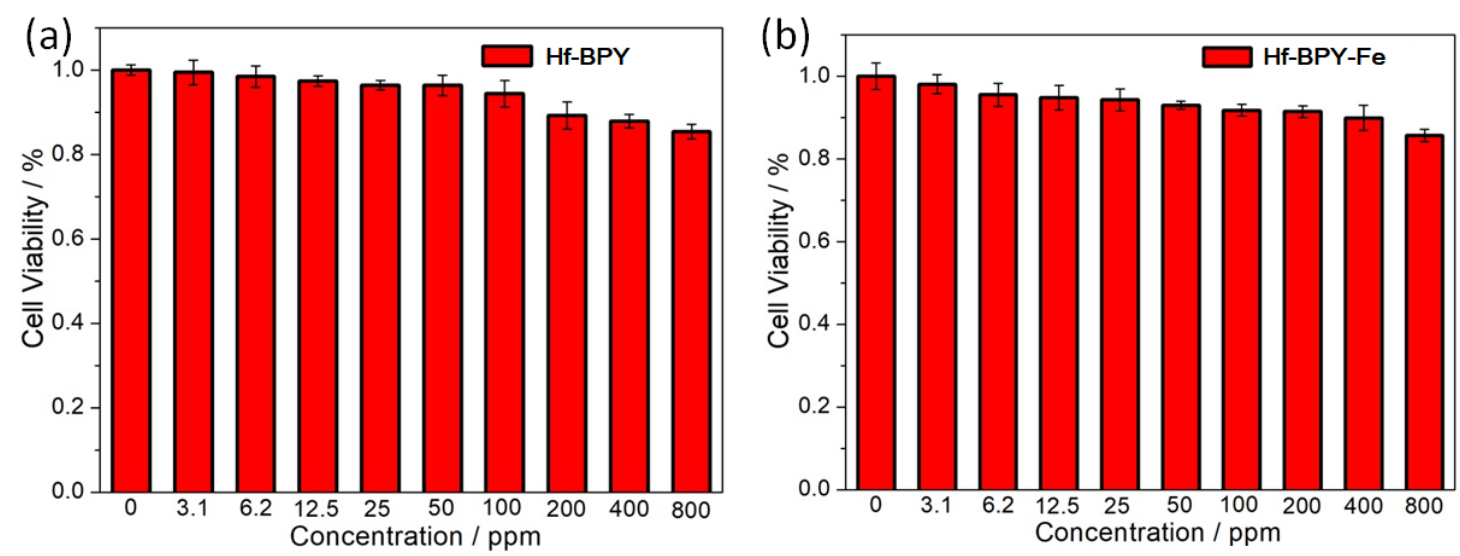

Figure S12. Cell viability of Hela cells after $24 \mathrm{~h}$ incubation with a series of concentrations (determined by ICP-OES based on the concentration of $\mathrm{Hf}^{4+}$ ions) of Hf-BPY and Hf-BPY-Fe.

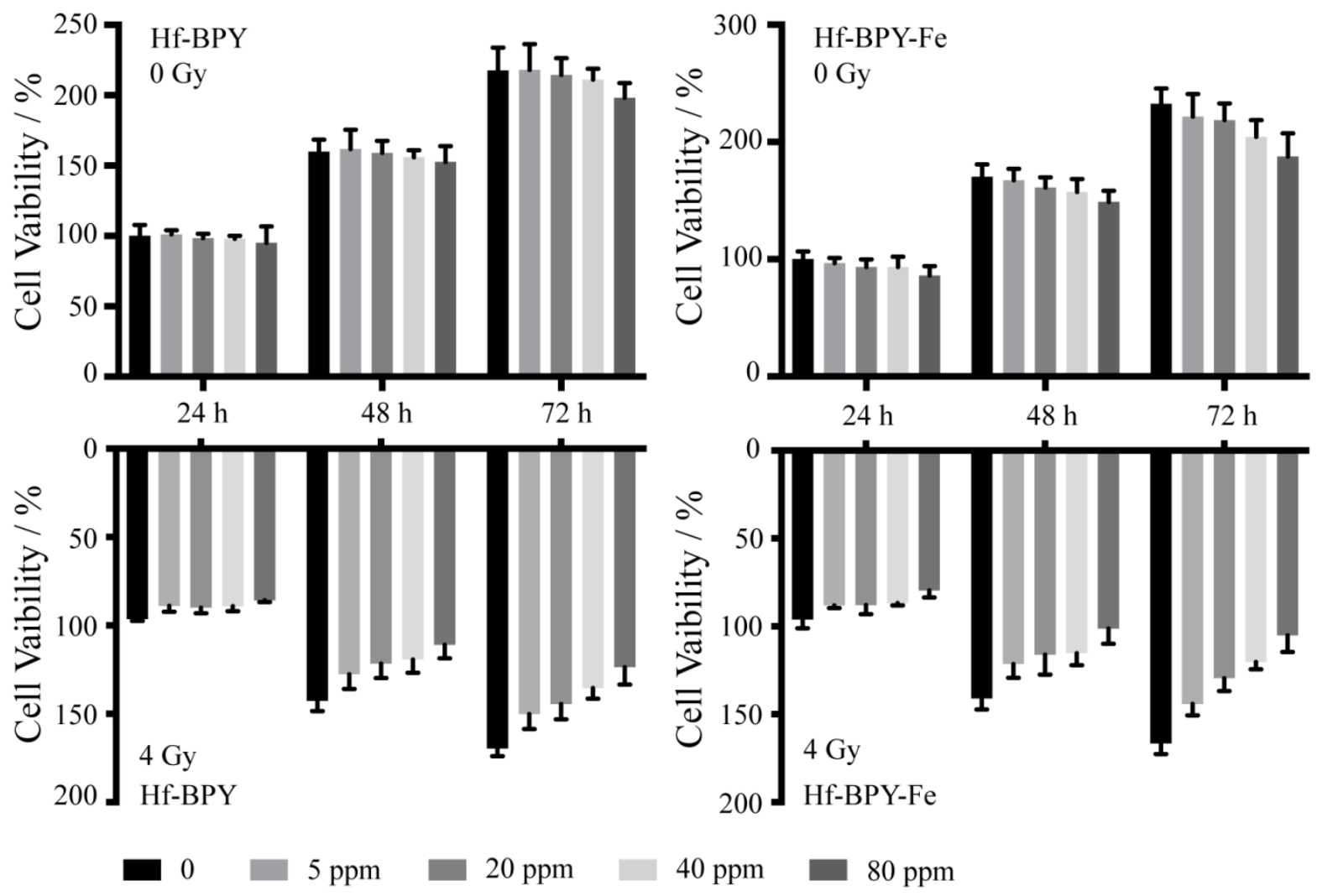

Figure S13. Cytotoxicity test in vitro of nMOFs. The Hela cells were seeded in 96-well plates (10000 cells per well) and incubated with a series of concentrations (determined by ICP-OES based on the concentration of $\mathrm{Hf}^{4+}$ ions) of Hf-BPY or Hf-BPY-Fe for $24 \mathrm{~h}$, PBS as blank 
control group. These cells were irradiated with $0 \mathrm{~Gy}$, or $4 \mathrm{~Gy}$ of X-rays. After that, the cells continued to incubate for other different times, $24 \mathrm{~h}, 48 \mathrm{~h}$ and $72 \mathrm{~h}$. MTT cell survival assay was applied to measure the survival rate of cells in each group.

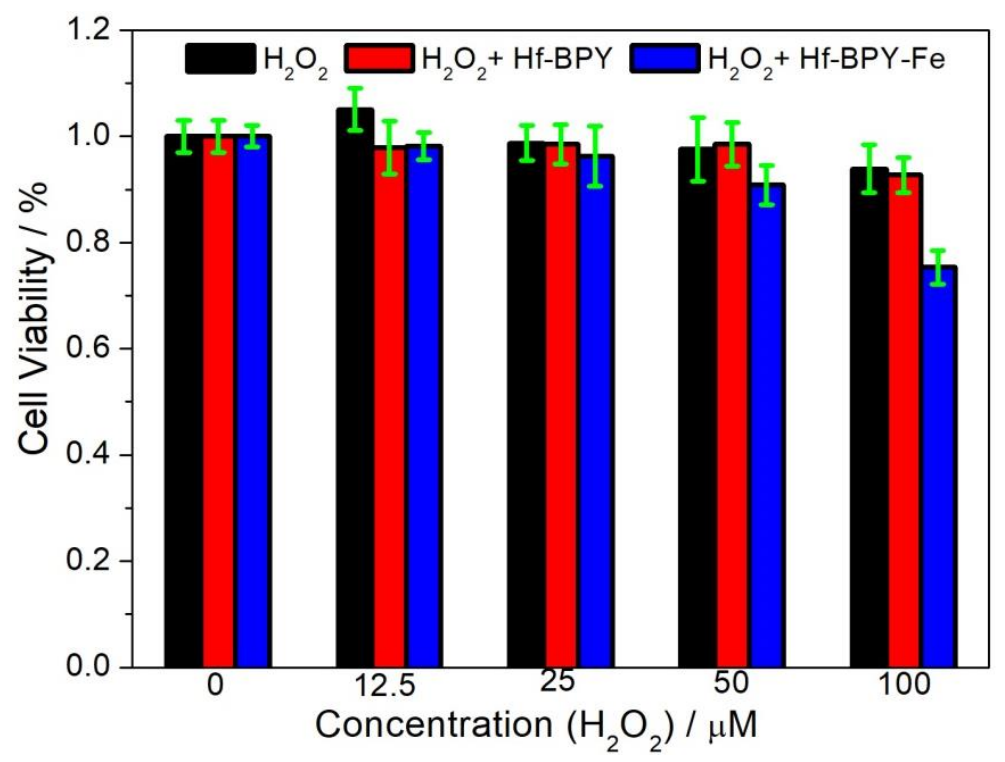

Figure S14. Cell viability of Hela cells after $24 \mathrm{~h}$ incubation with a series of concentrations of $\mathrm{H}_{2} \mathrm{O}_{2}$ and $\mathbf{H f}-\mathbf{B P Y}$ and Hf-BPY-Fe (5 ppm based on $\mathrm{Hf}^{4+}$ ions). External $\mathrm{H}_{2} \mathrm{O}_{2}$ was used to simulate the overexpression of $\mathrm{H}_{2} \mathrm{O}_{2}$ microenvironment in tumor area. The cell survival rate after CDT (induced by $50 \mu \mathrm{M} \mathrm{H}_{2} \mathrm{O}_{2}$ and $\mathbf{H f}-\mathbf{B P Y}-\mathbf{F e}$ ) was still higher than $80 \%$. Therefore, the safe dosage of $\mathrm{H}_{2} \mathrm{O}_{2}$ for all cell experiments in this work is $50 \mu \mathrm{M}$. 


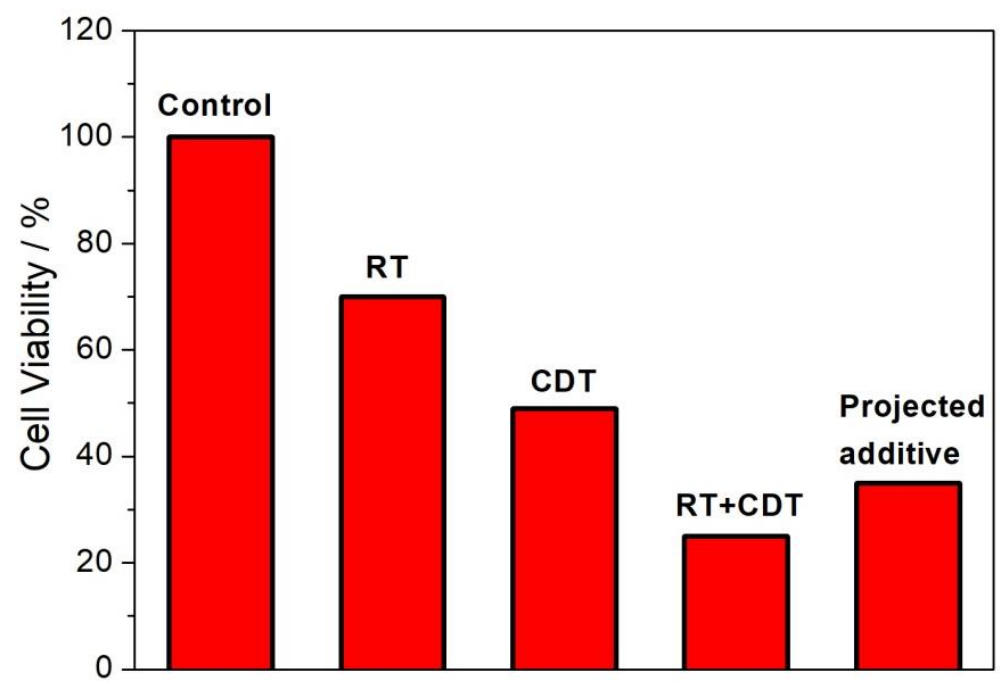

Figure S15. Synergistic therapeutic effect of Hela cells that have taken up Hf-BPY-Fe (80 ppm based on $\mathrm{Hf}^{4+}$ ions) subjected to $\mathrm{RT}, \mathrm{CDT}$, and the combined RT/CDT treatments. The projected additive value is calculated by multiplying the cell viability of RT and CDT group.
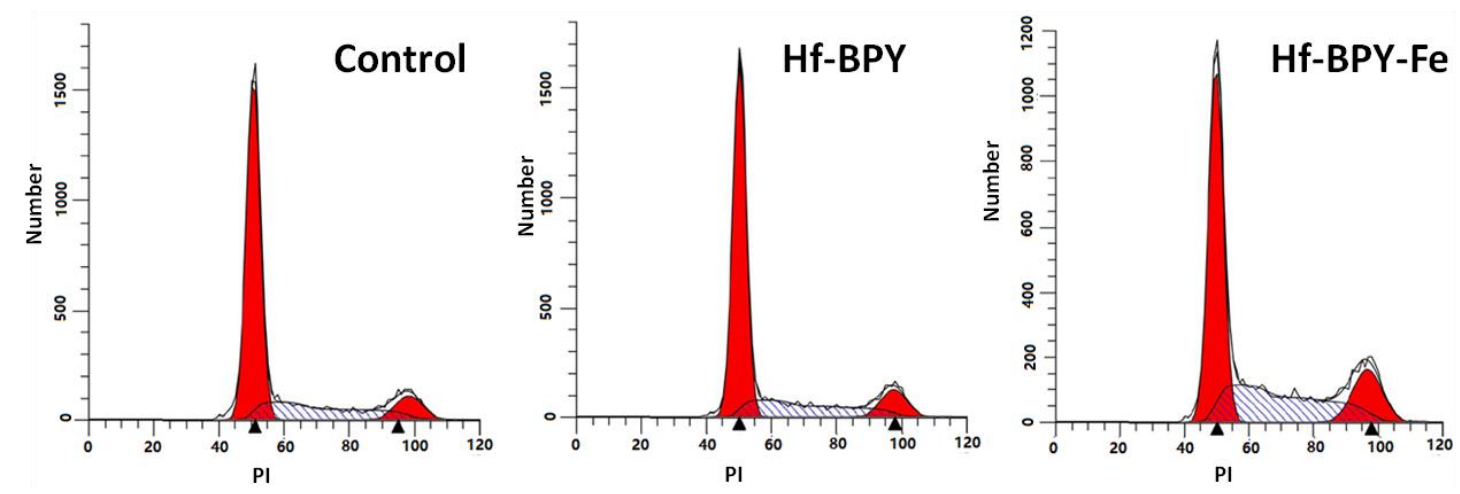

Figure S16. The flow cytometric analysis of cell cycles of Hela cells treated with PBS, Hf-BPY, and Hf-BPY-Fe for $24 \mathrm{~h}$, respectively. 

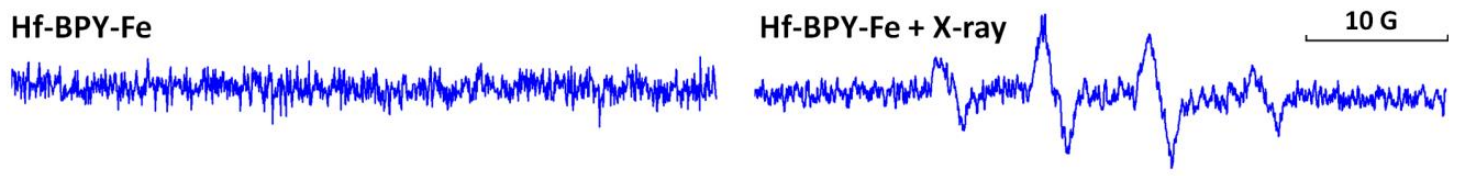

Hf-BPY

Hf-BPY + X-ray
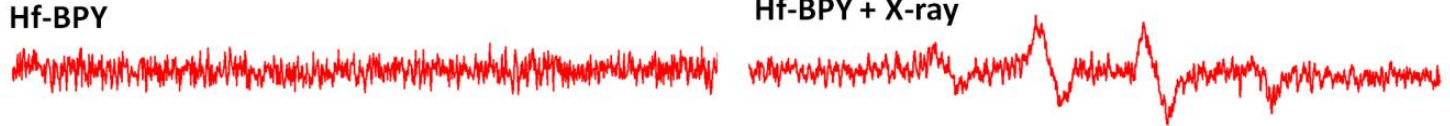

Figure S17. ESR spectra of different groups as indicated with/without X-ray irradiation (4 Gy). DMPO was used as the spin trap. Both of the two nMOFs shows representative $\cdot \mathrm{OH}$ signals after $\mathrm{X}$-ray treatment. The $\cdot \mathrm{OH}$ mainly come from water dissociation induced by strong X-ray attenuation of $\mathrm{Hf}^{4+}$ in nMOFs. After irradiation, ESR signal intensity of Hf-BPY-Fe is slightly stronger than Hf-BPY, which is consistent with the cell growth inhibition of nMOFs with X-ray treatment (Figure S13).
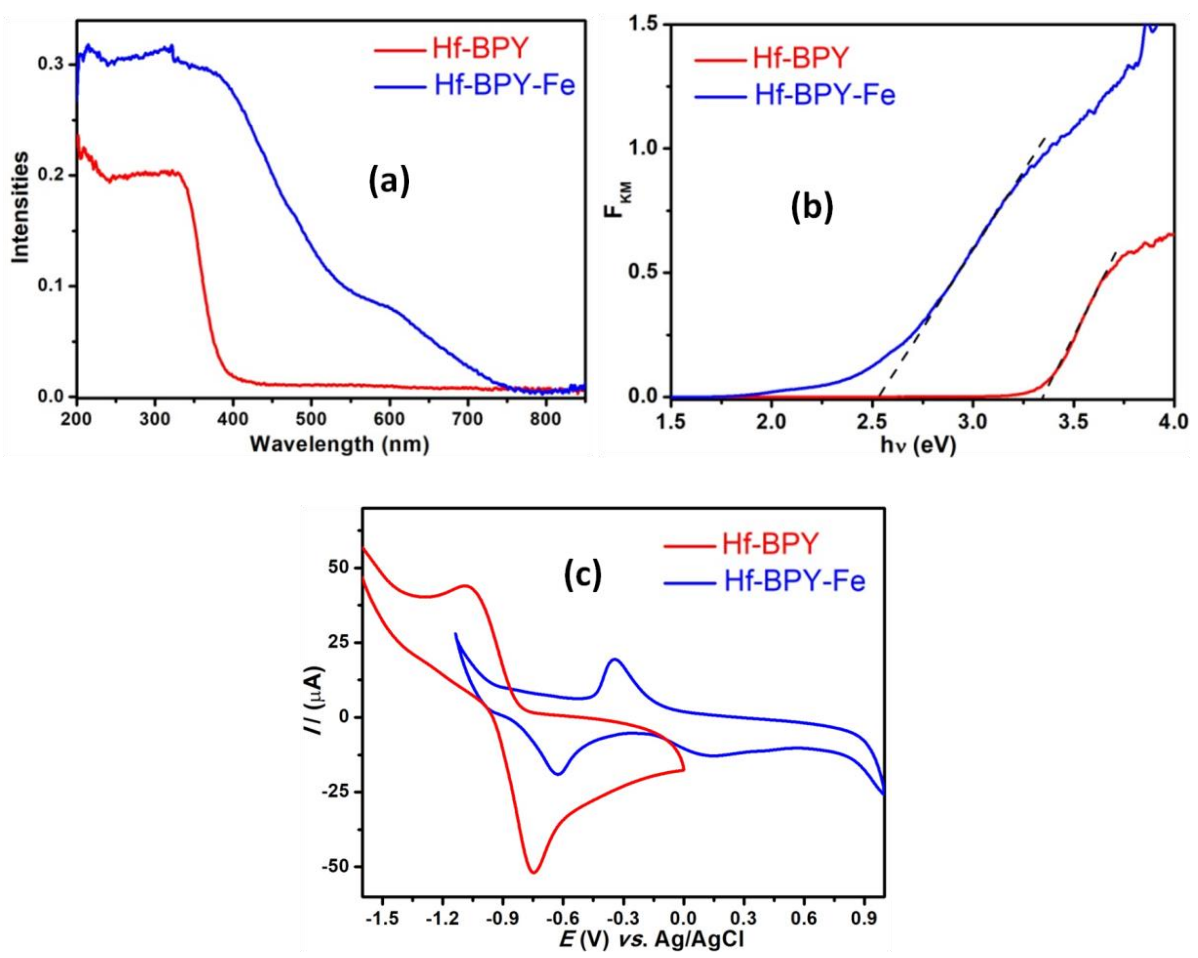

Figure S18. (a) Diffuse reflectance UV-vis spectra of Hf-BPY and Hf-BPY-Fe. (b) $F_{\mathrm{km}}$ spectra of nMOFs from diffuse reflectance UV-vis spectra. (c) Cyclic voltammograms of Hf-BPY and 
Hf-BPY-Fe. According to $E_{\text {LUMO }}(\mathrm{LUMO}=$ lowest unoccupied molecular orbital) estimated from the first reduction potential and $\Delta \mathrm{CT}$ estimated from the charge-transfer absorption in the solid-state UV-vis spectra. ${ }^{1,5}$
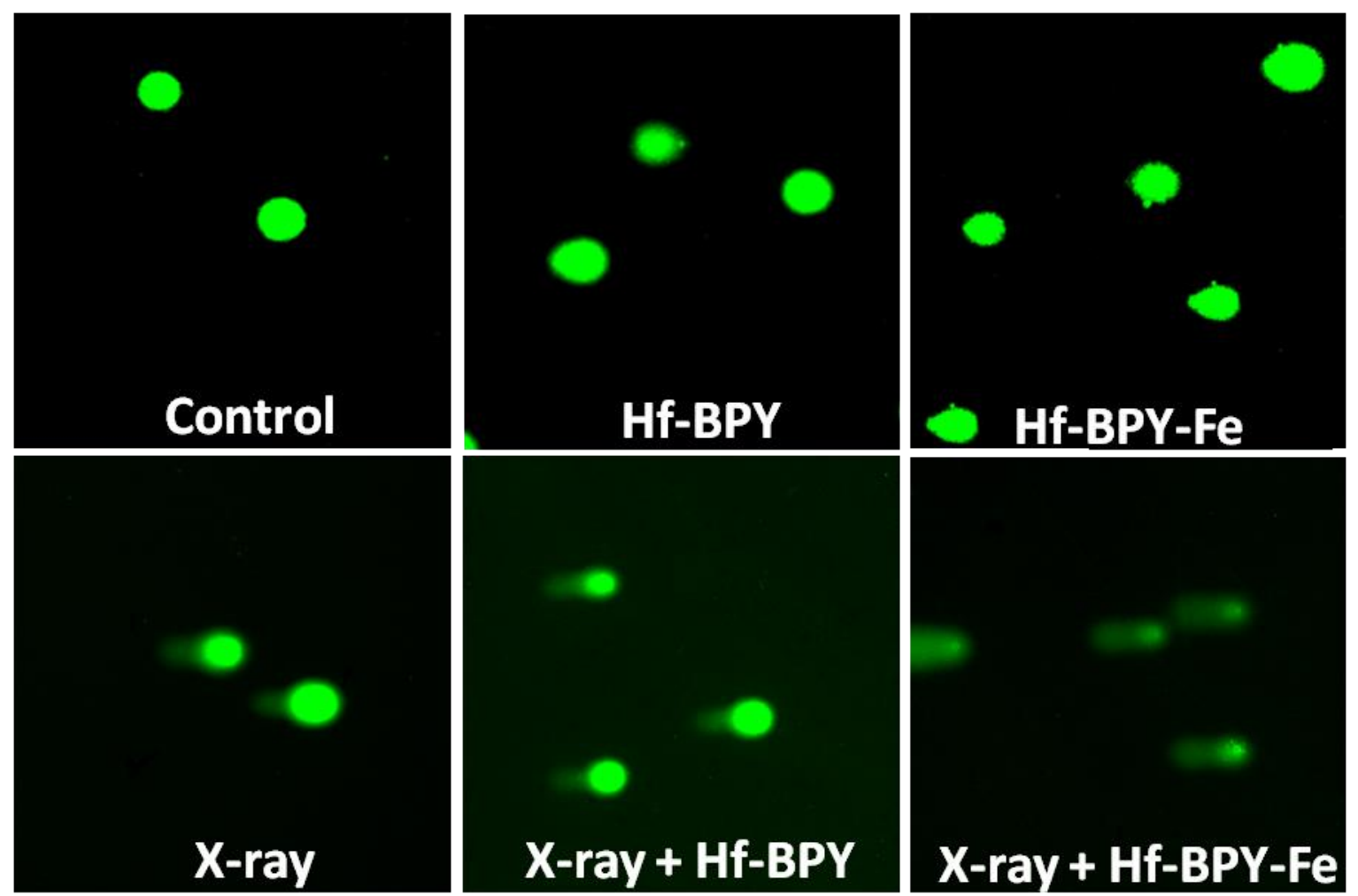

Figure S19. Comet assays after treatment with/without $\mathrm{X}$-ray radiation. Compared to other groups, the clear comet tails in the X-ray + Hf-BPY-Fe group suggest severe DNA damage in cells. These results are consistent with the results of the $\gamma-\mathrm{H} 2 \mathrm{AX}$ staining. 


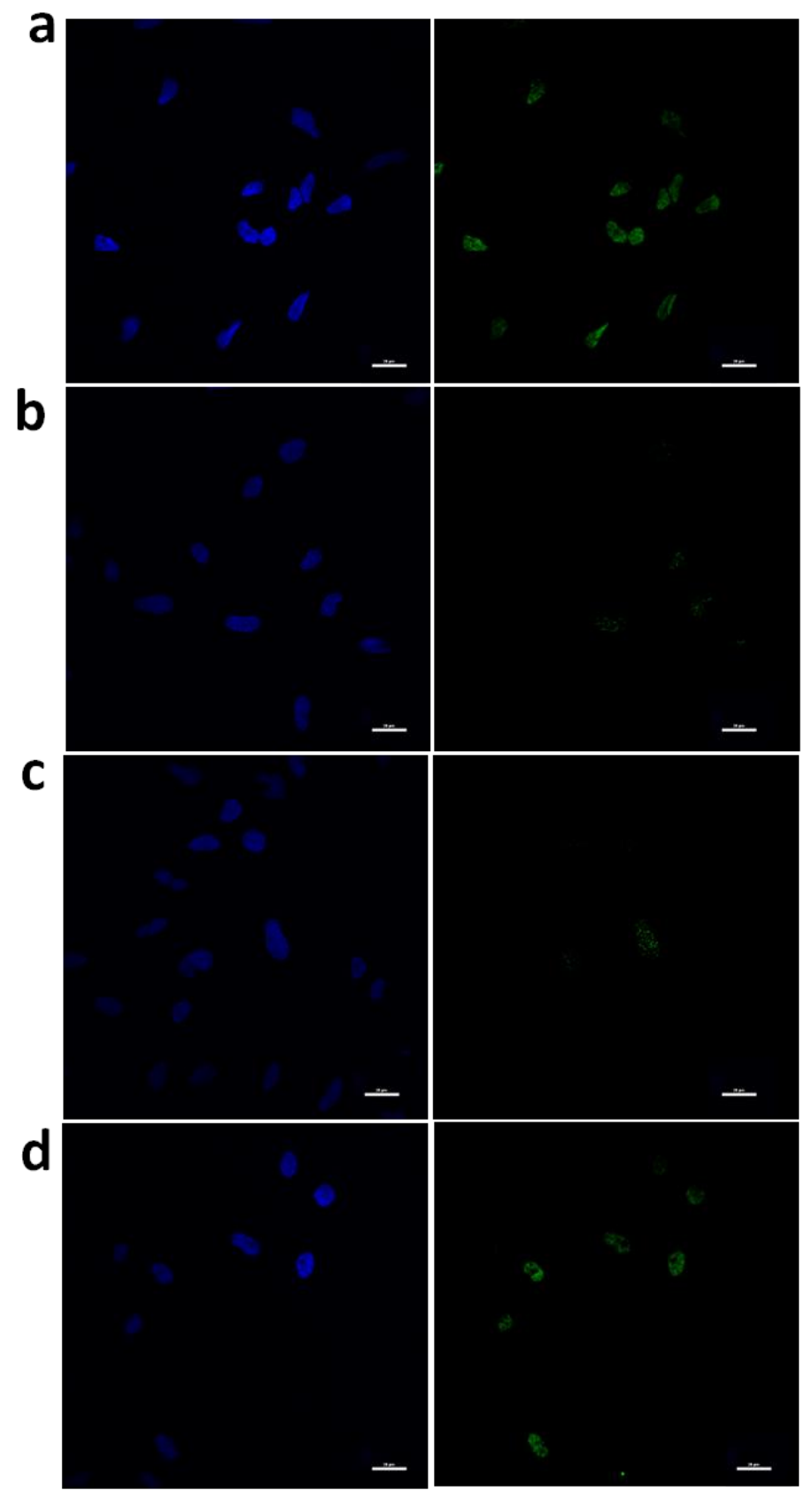

Figure S20. Detection of double-stranded DNA damage repair (Scale bar $=20 \mu \mathrm{m})$. The cells were irradiated with 6 Gy X-rays. Immunofluorescence images of $\gamma$-H2AX with different treatments: (a) detect immediately; detect after co-cultured for $24 \mathrm{~h}$ with PBS (b), Hf-BPY (c), or Hf-BPY-Fe (d). 

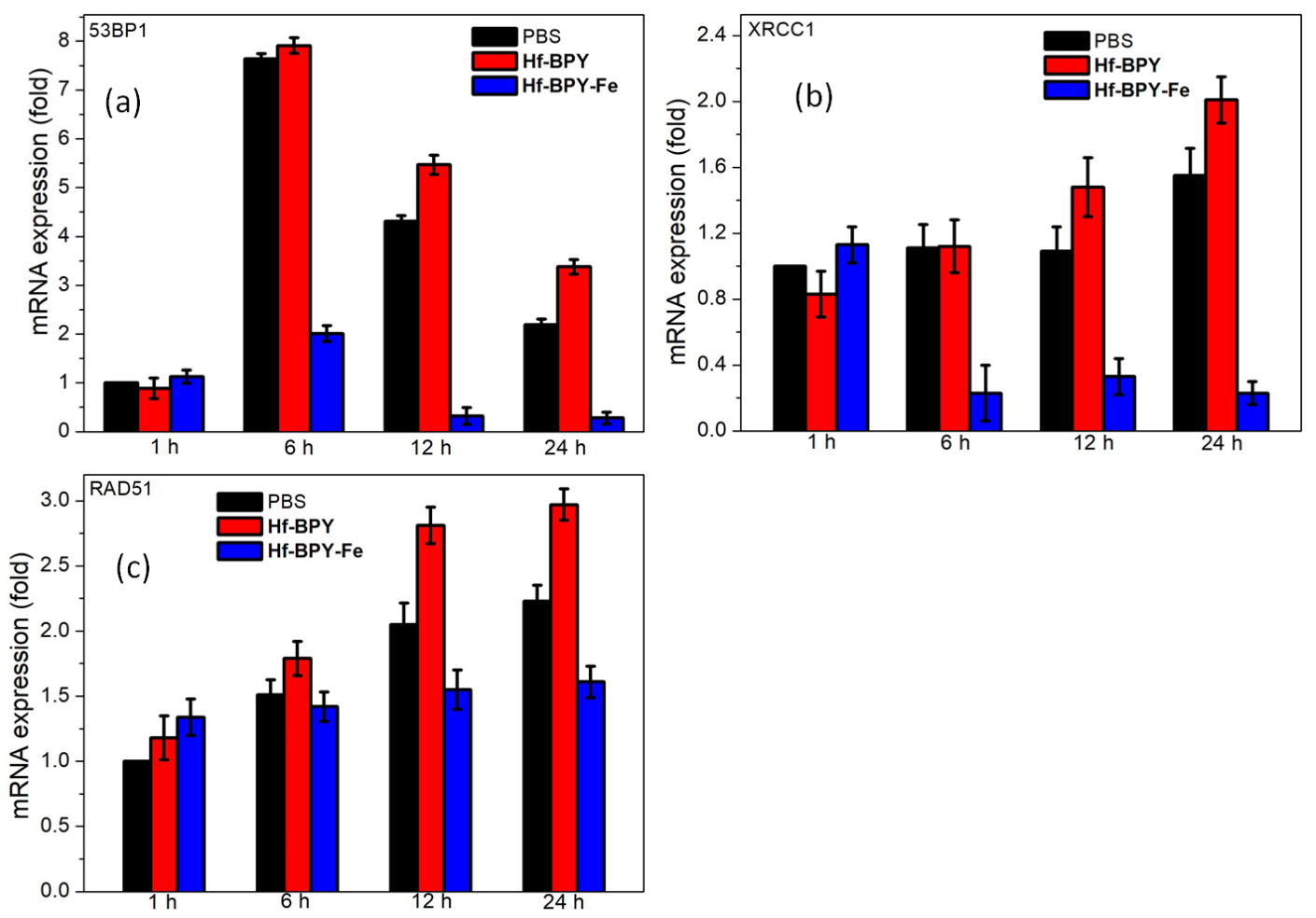

Figure S21. Real time PCR results of different groups including 53BP1, XRCC1 and RAD51. 


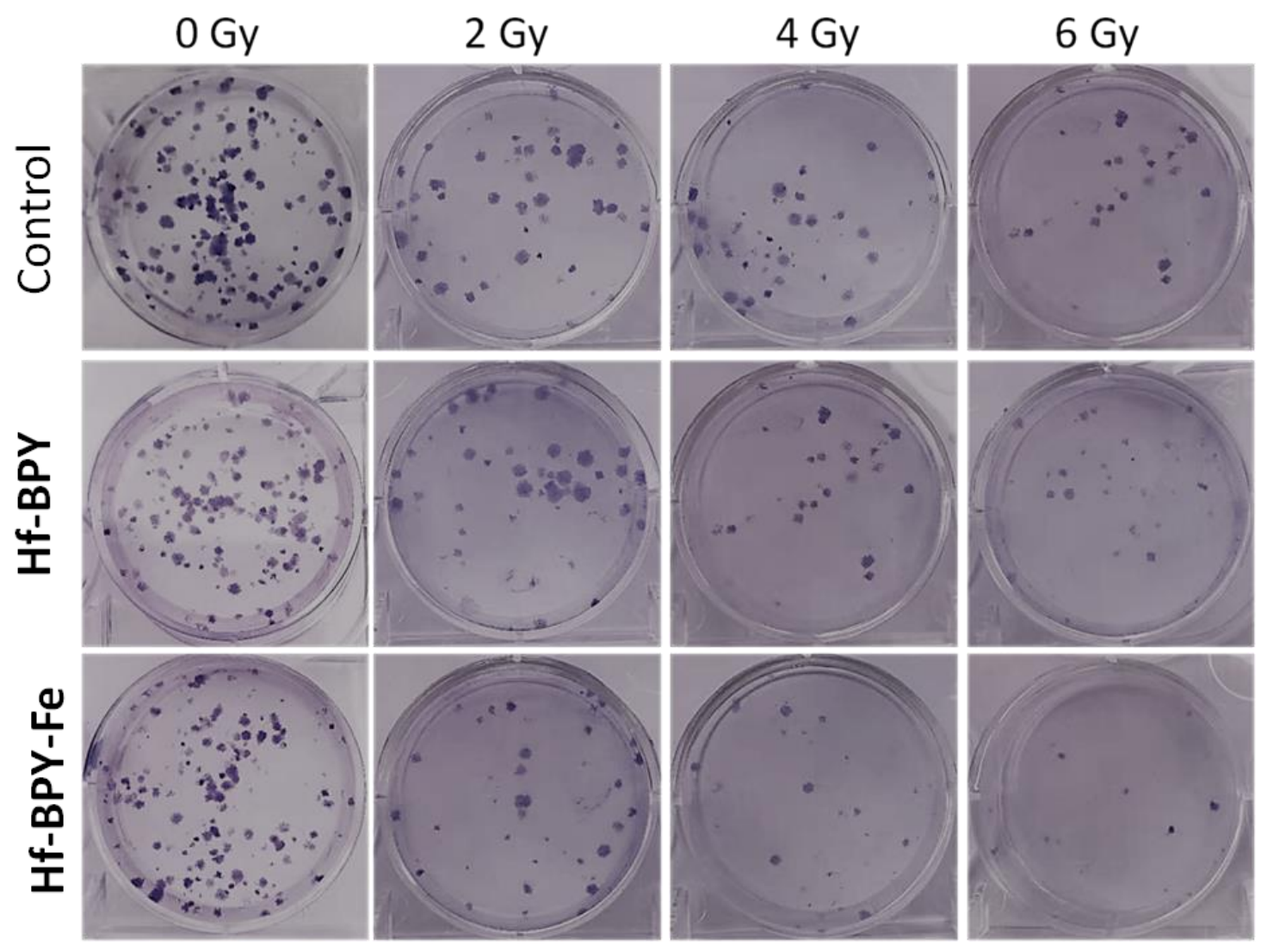

Figure S22. Colony formation assay of Hela cells incubated with PBS, Hf-BPY or Hf-BPY-Fe with or without X-ray irradiation. 

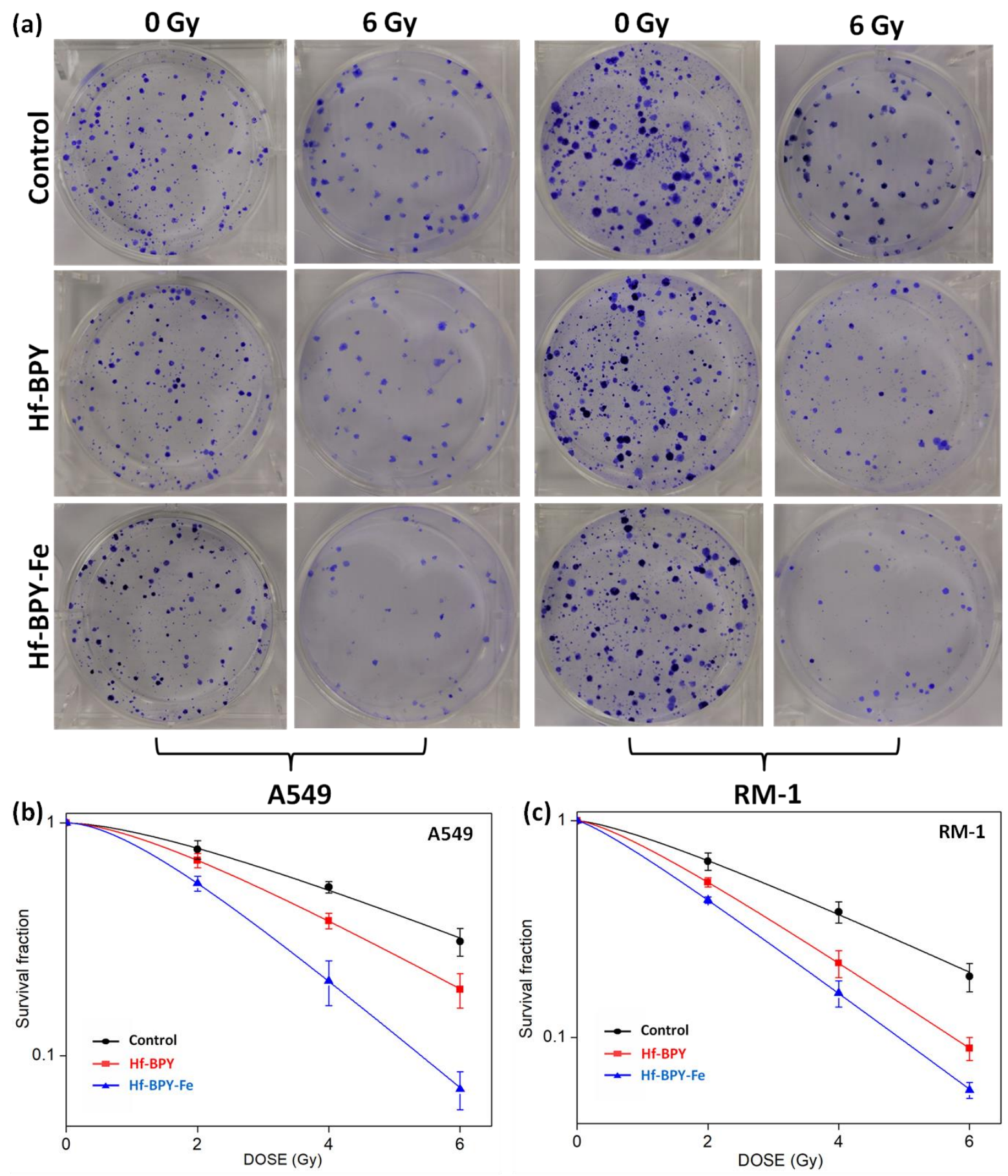

Figure S23. Colony formation assay of A549 and RM-1 cells lines. 
Table S1. Sensitization enhancement ratio (SER) values by clonogenic assays in a panel of cell lines upon X-ray irradiation.

\begin{tabular}{lccc}
\hline SER & Hela & A549 & RM-1 \\
\hline Hf-BPY & 1.41 & 1.32 & 1.43 \\
Hf-BPY-Fe & 1.74 & 1.87 & 1.75 \\
\hline
\end{tabular}

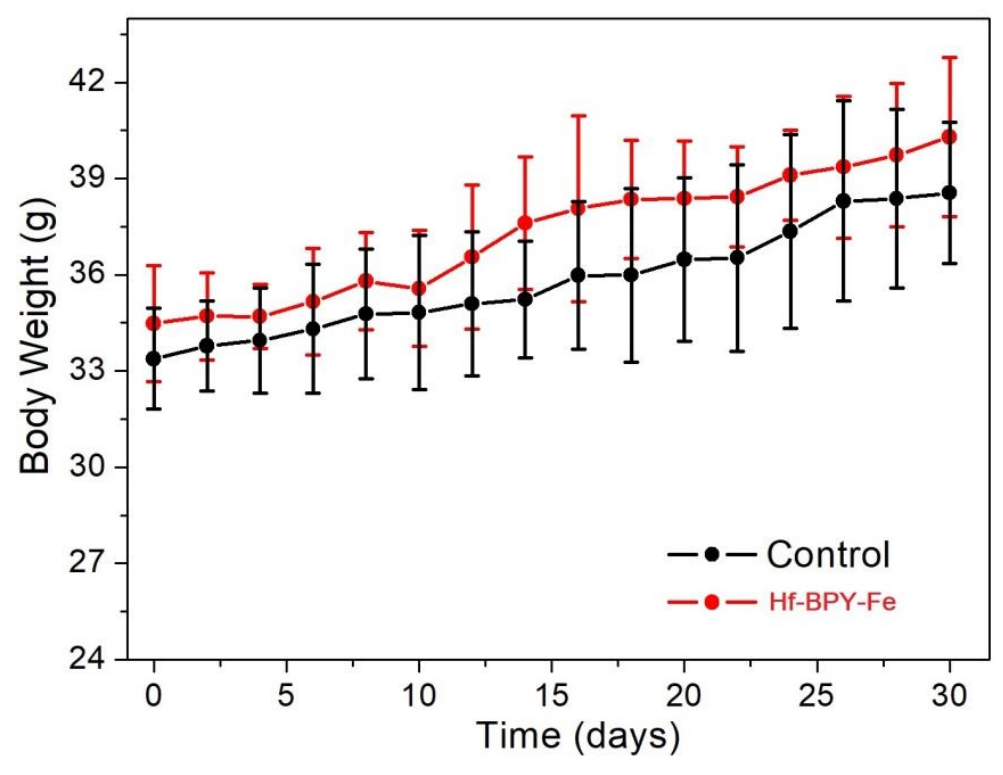

Figure S24. Temporal changes of body weight of Kunming mice after intravenous injection of Hf-BPY-Fe (Hf, $100 \mathrm{mg} / \mathrm{kg})$ or PBS. 

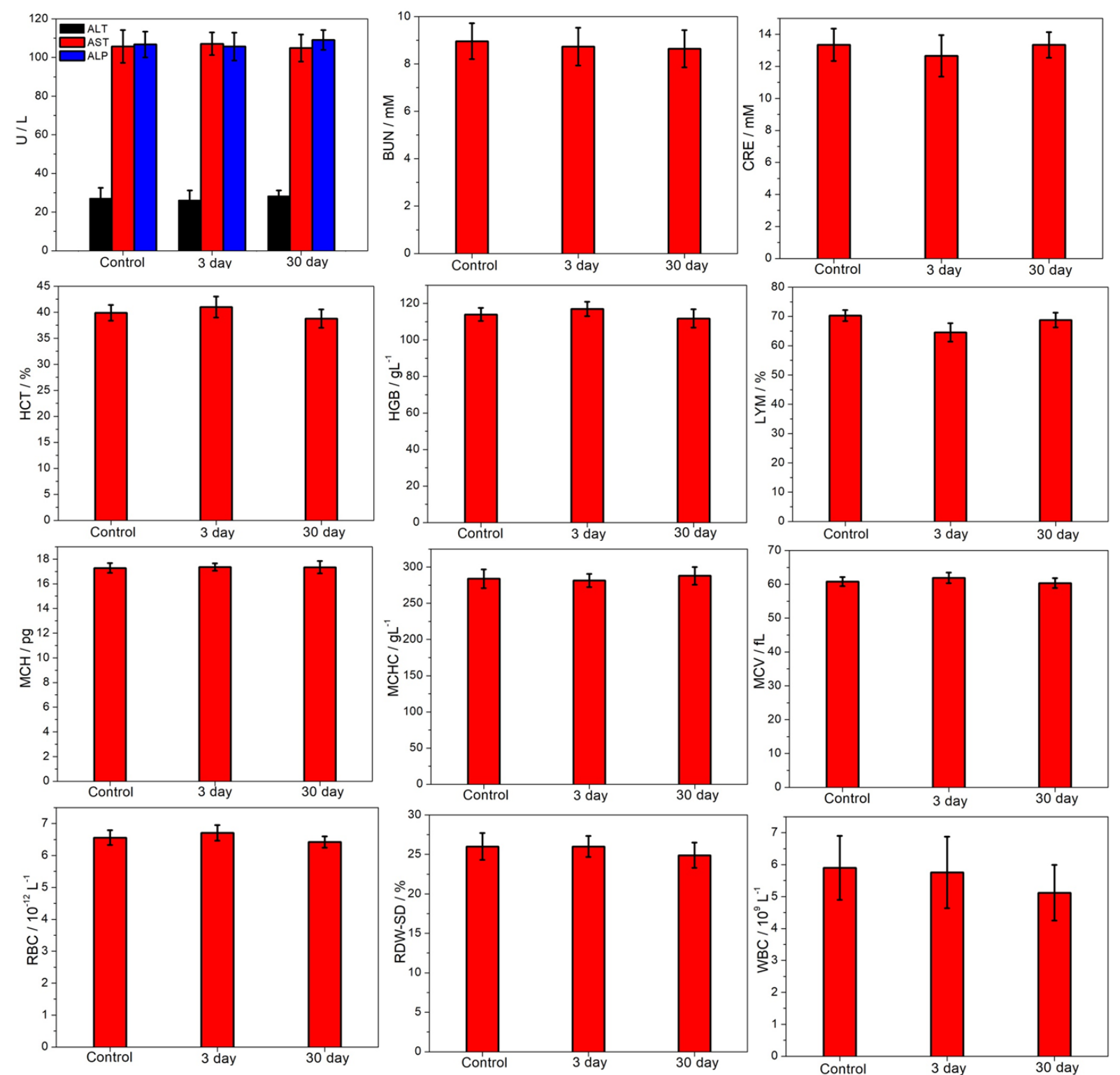

Figure S25. Hematological parameters of Kunming mice after intravenous injection of Hf-BPY-

Fe (Hf, $100 \mathrm{mg} / \mathrm{kg})$ or PBS. 


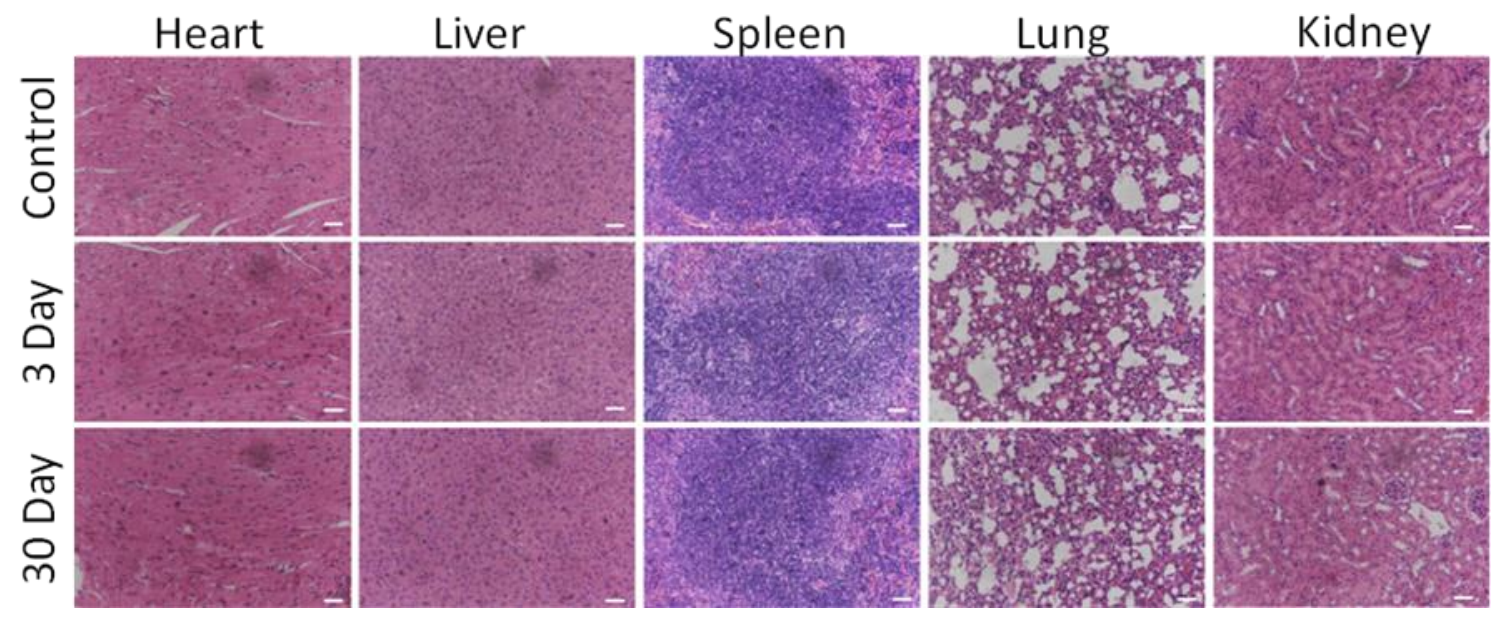

Figure S26. Hematoxylin-Eosin (H\&E) stained tissue sections of major organs of Kunming mice after intravenous injection of Hf-BPY-Fe (Hf, $100 \mathrm{mg} / \mathrm{kg})$. Scale bar $=50 \mu \mathrm{m}$

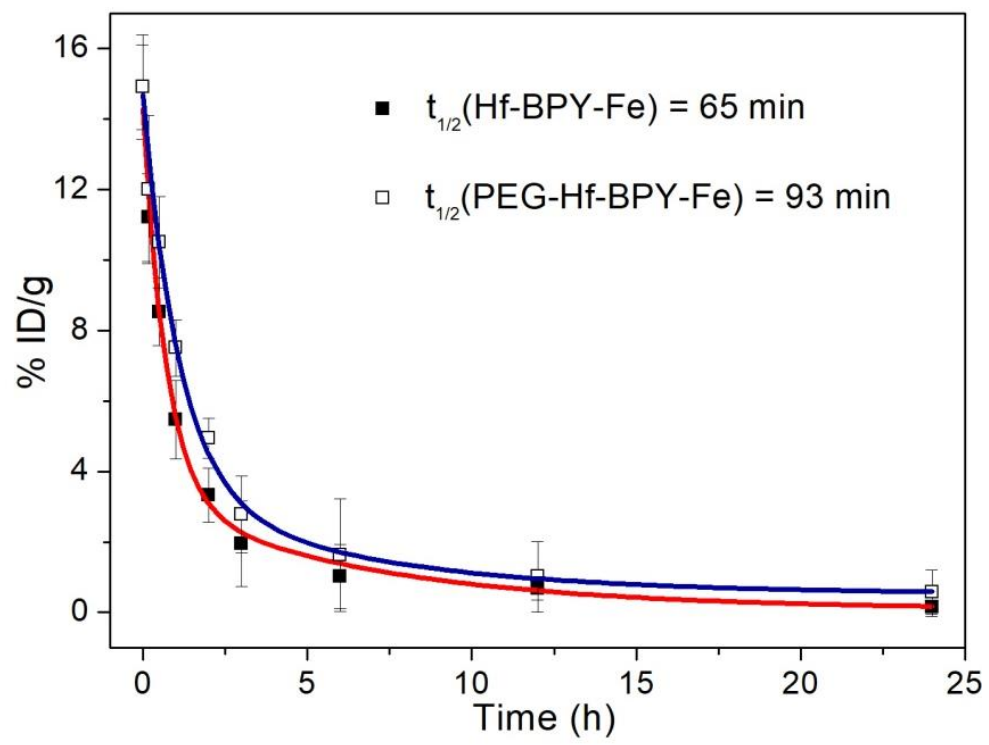

Figure S27. Blood half-time test of Hf element. The blood terminal half-life of Hf-BPY-Fe and PEG-Hf-BPY-Fe is $65 \mathrm{~min}$ and $93 \mathrm{~min}$, respectively, based on the one-component pharmacokinetic model. Three female Balb/c nude mice at 7 weeks were injected intravenously with Hf-BPY-Fe and PEG-Hf-BPY-Fe (Hf, $100 \mathrm{mg} / \mathrm{kg}$ ) saline solution, respectively. After that, $20 \mu \mathrm{L}$ blood was collected from the tail vein in the given time points $(10 \mathrm{~min}, 30 \mathrm{~min}, 1 \mathrm{~h}, 2 \mathrm{~h}, 3$ $\mathrm{h}, 6 \mathrm{~h}, 12 \mathrm{~h}$ and $24 \mathrm{~h}$ ) and diluted to $4 \mathrm{ml}$ of ultrapure water with $10 \mathrm{mM}$ 
ethylenediaminetetraacetic acid disodium salt (EDTA-2Na) as anticoagulant. Then ICP-OES was used to determine the time-dependent concentrations of $\mathrm{Hf}$ in blood. ${ }^{6}$ The prolonged circulation time of nanoparticles in blood could be attributed to surface modification of PEG reduces uptake in reticuloendothelial system (RES).-8

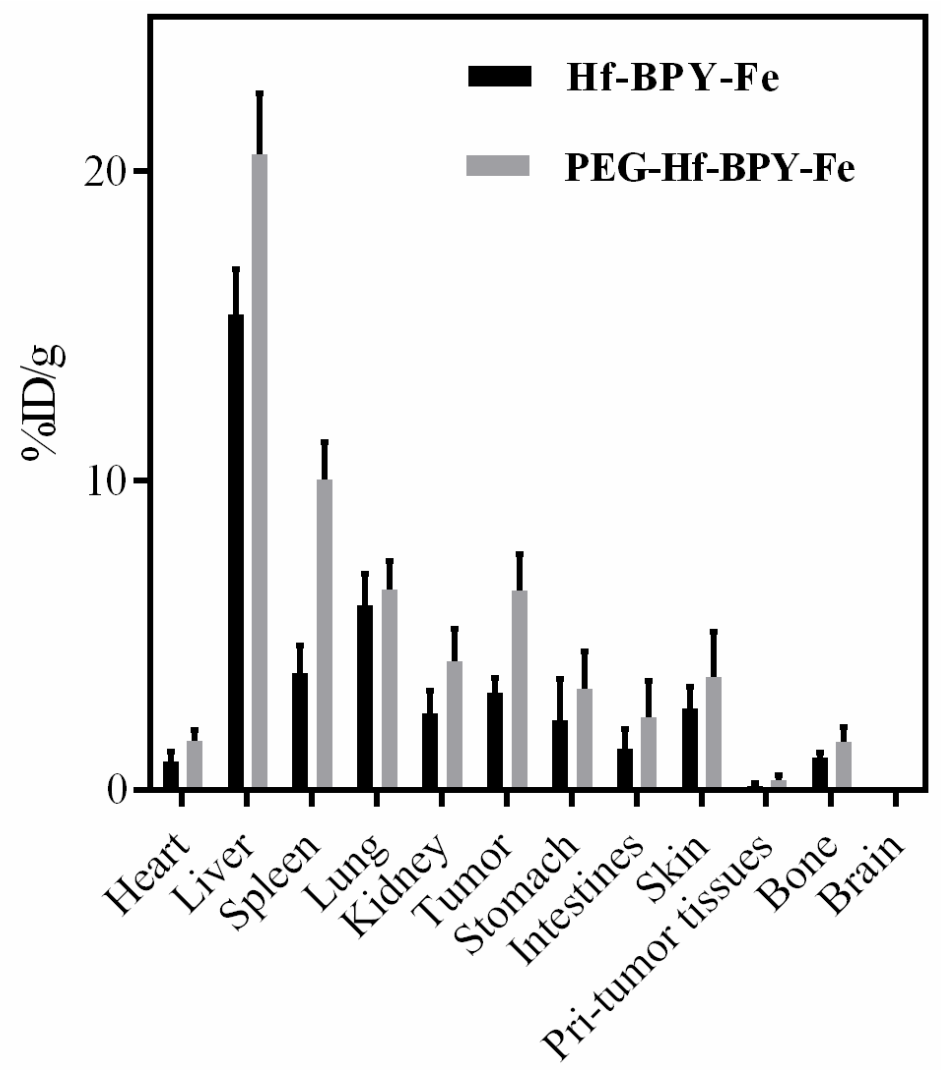

Figure S28. Biodistribution of $\mathrm{Hf}$ in Balb/c nude mice. Three female Balb/c nude mice at 7 weeks were injected intravenously with Hf-BPY-Fe or PEG-Hf-BPY-Fe (Hf, $100 \mathrm{mg} / \mathrm{kg}$ ) saline solution. After 24h, the mice were sacrificed and the major organs, tumors and muscles adjacent to tumor were collected. These tissues and organs were weighted and then digested with aqua regia for ICP-OES analysis of $\mathrm{Hf}$ content. The percentage injected dose per gram (\% ID g ${ }^{-1}$ ) organ/tissue $(D)$ of Hf was calculated by the following equation: ${ }^{9}$ 


$$
D=\frac{\mathrm{M}_{\mathrm{Hf}} / \mathrm{M}_{\text {organ }}}{\mathrm{M}_{\mathrm{ID}}} \times 100 \%
$$

where $\mathrm{M}_{\mathrm{Hf}}(\mu \mathrm{g})$ is the mass in the corresponding organ whose mass is $\mathbf{M}_{\text {organ }}(\mathrm{g})$, and the constant $\mathrm{MID}_{\mathrm{ID}}(\mu \mathrm{g})$ is the injected dose of Hf.

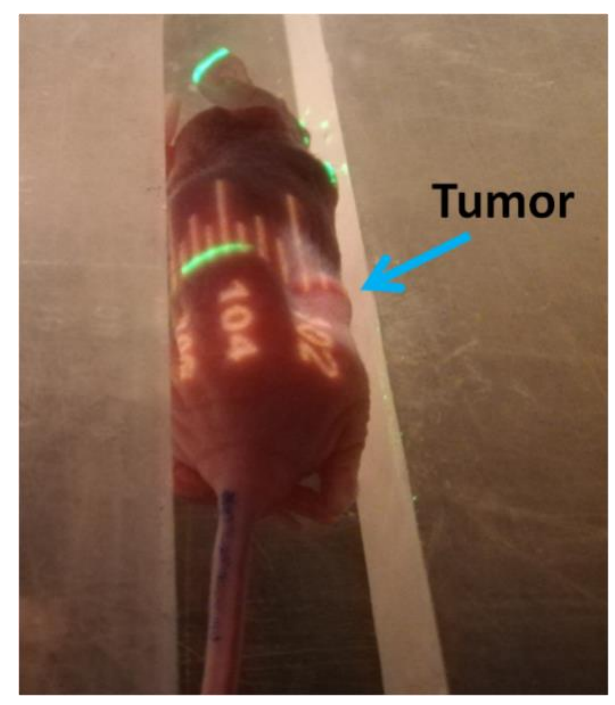

Figure S29. Localization of tumor in the clinical radiation therapy apparatus.

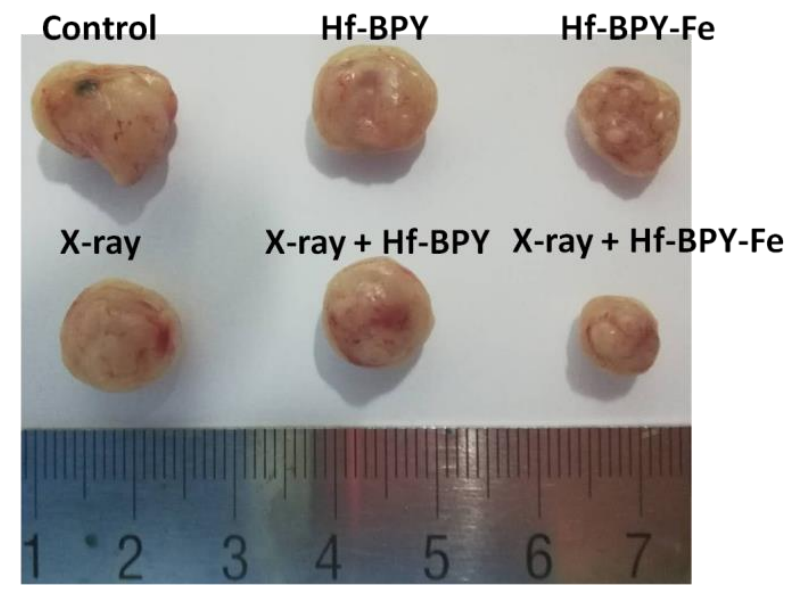

Figure S30. Tumor photos at the end of the observation. 
(a)

잉
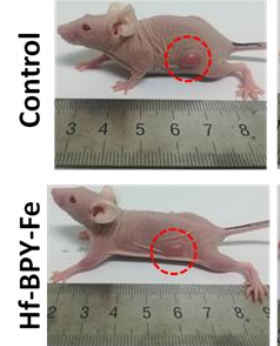

(-)
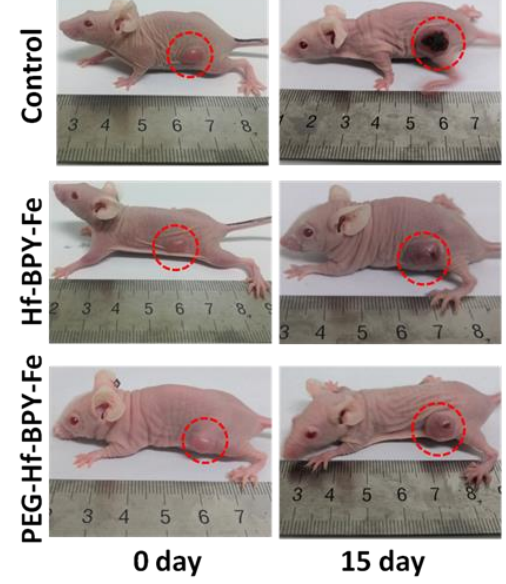

15 day
(+)

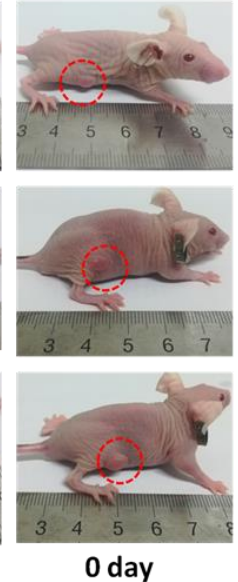

(+)

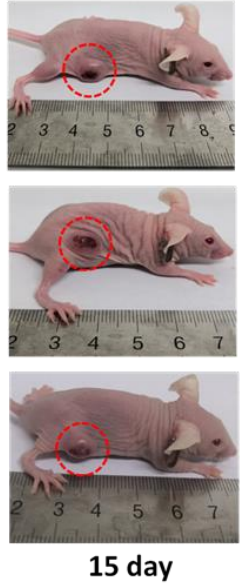

(b)

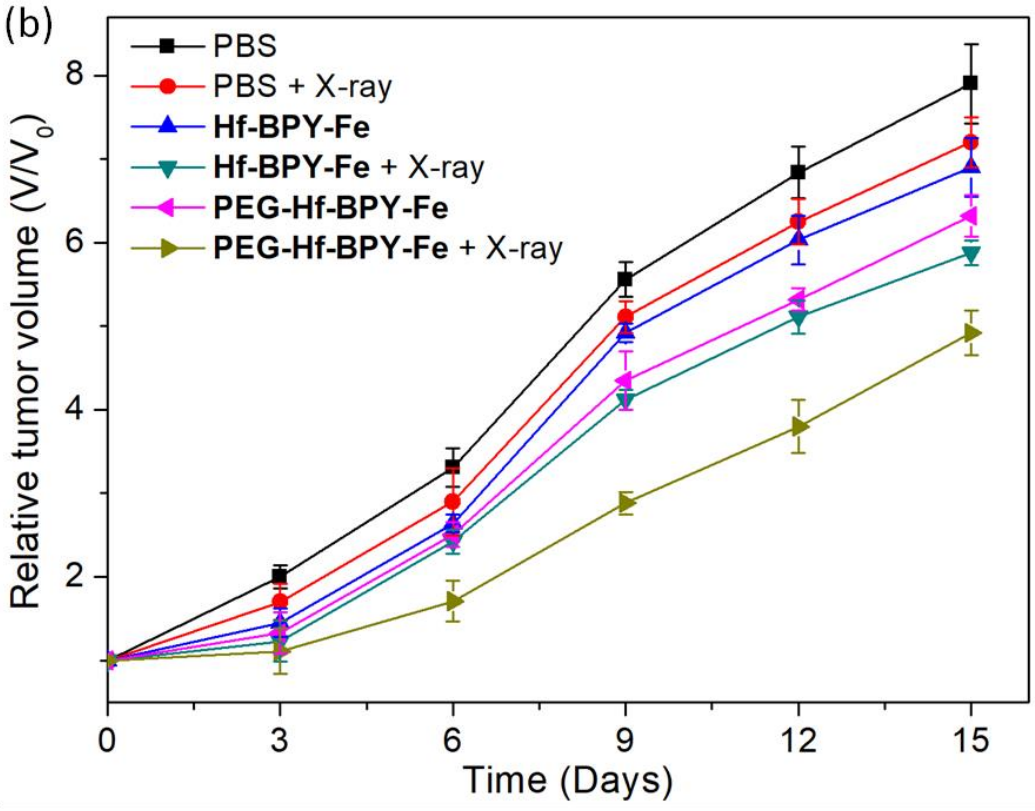

Figure S31. Photographs of xenograft tumors (a) and growth curves (b) after different treatments via intravenous injection. 


\section{REFERENCES}

1. Sippel, P.; Denysenko, D.; Loidl, A.; Lunkenheimer, P.; Sastre, G.; Volkmer, D. Dielectric Relaxation Processes, Electronic Structure, and Band Gap Engineering of MFU-4Type Metal-Organic Frameworks: Towards a Rational Design of Semiconducting Microporous Materials. Adv. Funct. Mater. 2014, 24, 3885-3896.

2. Wood, D. L.; Tauc, J. Weak Absorption Tails in Amorphous Semiconductors. Phys. Rev. B 1972, 5, 3144-3151.

3. Ma, N.; Jiang, Y. W.; Zhang, X.; Wu, H.; Myers, J. N.; Liu, P.; Jin, H.; Gu, N.; He, N.; Wu, F. G.; Chen, Z. Enhanced Radiosensitization of Gold Nanospikes via Hyperthermia in Combined Cancer Radiation and Photothermal Therapy. ACS Appl. Mater. Interfaces 2016, 8, 28480-28494.

4. Yang, N. N.; Fang, J. J.; Sui, Q.; Gao, E. Q. Incorporating Electron-Deficient Bipyridinium Chromorphores to Make Multiresponsive Metal-Organic Frameworks. ACS Appl. Mater. Interfaces 2018, 10, 2735-2744.

5. Cardona, C. M.; Li, W.; Kaifer, A. E.; Stockdale, D.; Bazan, G. C. Electrochemical Considerations for Determining Absolute Frontier Orbital Energy Levels of Conjugated Polymers for Solar Cell Applications. Adv. Mater. 2011, 23, 2367-2371.

6. Zhang, C.; Bu, W.; Ni, D.; Zhang, S.; Li, Q.; Yao, Z.; Zhang, J.; Yao, H.; Wang, Z.; Shi, J. Synthesis of Iron Nanometallic Glasses and Their Application in Cancer Therapy by a Localized Fenton Reaction. Angew. Chem., Int. Ed. 2016, 55, 2101-2106.

7. Vert, M.; Domurado, D. Poly(Ethylene Glycol): Protein-Repulsive or AlbuminCompatible? J. Biomater. Sci., Polym. Ed. 2000, 11, 1307-1317.

8. Blume, G.; Cevc, G.; Crommelin, M. D. J. A.; Bakker-Woudenberg, I. A. J. M.; Kluft, C.; Storm, G. Specific Targeting with Poly(Ethylene Glycol)-Modified Liposomes: Coupling of Homing Devices to the Ends of the Polymeric Chains Combines Effective Target Binding with Long Circulation Times. Biochim. Biophys. Acta 1993, 1149, 180-184.

9. Zhang, C.; Bu, W.; Ni, D.; Zuo, C.; Cheng, C.; Li, Q.; Zhang, L.; Wang, Z.; Shi, J. A Polyoxometalate Cluster Paradigm with Self-Adaptive Electronic Structure for Acidity/Reducibility-Specific Photothermal Conversion. J. Am. Chem. Soc. 2016, 138, 81568164. 